\title{
Brain functioning under acute hypothermic stress supported by dynamic monocarboxylate utilization and transport in ectothermic fish
}

\author{
Yung-Che Tseng ${ }^{1 \dagger}$, Sian-Tai Liu ${ }^{1 \dagger}$, Marian Y Hư ${ }^{2 \dagger}$, Ruo-Dong Chen², Jay-Ron Lee ${ }^{2}$ and Pung-Pung Hwang ${ }^{2 *}$
}

\begin{abstract}
Background: The vertebrate brain is a highly energy consuming organ that requires continuous energy provision. Energy metabolism of ectothermic organisms is directly affected by environmental temperature changes and has been demonstrated to affect brain energy balance in fish. Fish were hypothesized to metabolize lactate as an additional energy substrate during acute exposure to energy demanding environmental abiotic fluctuations to support brain functionality. However, to date the pathways of lactate mobilization and transport in the fish brain are not well understood, and may represent a critical physiological feature in ectotherms during acclimation to low temperature.

Results: We found depressed routine metabolic rates in zebrafish during acute exposure to hypothermic $\left(18^{\circ} \mathrm{C}\right)$ conditions accompanied by decreased lactate concentrations in brain tissues. No changes in brain glucose content were observed. Acute cold stress increased protein concentrations of lactate dehydrogenase 1 (LDH1) and citrate synthase (CS) in brain by 1.8- and-2.5-fold, paralleled by an increased pyruvate to acetyl-CoA transformation. To test the involvement of monocarboxylate transporters (MCTs) under acute cold stress in zebrafish, we cloned and sequenced seven MCT1-4 homologues in zebrafish. All drMCT1-4 are expressed in brain tissues and in response to cold stress drmct2a and drmct4a transcripts were up-regulated 5- and 3-fold, respectively. On the contrary, mRNA levels of drmct $1 a,-1 b$ and $-4 b$ in zebrafish brain responded with a down regulation in response to cold stress. By expressing drMCTs in Xenopus oocytes we could provide functional evidence that hypothermic stress leads to a 2 -fold increase in lactate transport in drMCT4b expressing oocytes. Lactate transport of other paralogues expressed in oocytes was unaffected, or even decreased during cold stress.
\end{abstract}

Conclusion: The present work provides evidence that lactate utilization and transport pathways represent an important energy homeostatic feature to maintain vital functions of brain cells during acute cold stress in ectotherms.

Keywords: Monocarboxylate transporter, Cold stress, Energy homeostasis, Brain, Ectotherms

\section{Background}

Fluctuating environmental temperatures are a major stressor for ectothermic animals which can severely affect vital biochemical and physiological processes [1,2]. Ectothermic organisms have evolved a range of mechanisms to maintain physiological functions during environmental temperature fluctuations $[1,3,4]$. In the context of hypothermic tolerance special attention has been dedicated

\footnotetext{
* Correspondence: pphwang@gate.sinica.edu.tw

'Equal contributors

${ }^{2}$ Institute of Cellular and Organismic Biology, Academia Sinica, Nankang,

Taipei City, Taiwan

Full list of author information is available at the end of the article
}

to energy metabolism related processes. For example, in blood and liver of common eelpout (Zoarces viviparus), the levels of adenosine were elevated under cold stress via adenosine-triphosphate (ATP) hydrolysis indicating that immediate energy supply and the activation of associated enzymes are essential for ectothermic animals undergoing hypothermic acclimation [5]. Furthermore the utilization of lactate to generate energy equivalents has been hypothesized to represent an essential adaptive mechanism to support cellular and organismic functionality during hypothermic stress. For example, Antarctic fish brains were demonstrated to have higher activities of lactate dehydrogenases (LDH) and citrate synthases (CS) when 
compared to tropical and subtropical species $[6,7]$. Neuronal functions may thus remain regular and wellcoordinated by maintaining metabolic rates in brain tissues during cold acclimation. For example, in isolated brain slices of teleost fishes, high oxygen consumption rates during cold acclimation have been reported $[7,8]$. These results suggest that at least a partial compensation to cold stress may exist, which is fueled by aerobic ATP producing pathways in fish brain. Moreover, earlier studies using zebrafish could demonstrate a mild mitochondrial uncoupling resulting in enhanced heat production in brain during acute cold stress [1]. Additionally increased activation of glucose transporter (GLUT) and ATP production via glycolysis has been suggested to allow for a metabolic shift to maintain physiological energy balance in brains of zebrafish under acute cold stress [1]. Therefore it was concluded that despite reductions in metabolic rate on the whole animal level, cold acclimated/ adapted fish need to maintain brain energy homeostasis by temperature-compensatory mechanism to support proper functionality. This suggests that brain tissues have evolved compensatory metabolic features that allow fish to maintain brain functionality in a hypothermic environment [6-8].

The brain is a highly energy consuming organ and very sensitive to fluctuations in energy supply $[9,10]$. Most energy consumed by brain cells is devoted to message signal transduction, systemic endocrine regulation, ionic gradient maintenance and restoration after depolarization [11-13]. The brain belongs to the central nervous system and is encased in fluid-filled meninges which consist of neurons, glial cells and capillaries separated from other tissues by a blood-brain barrier (BBB) $[10,14]$. High concentrations of GLUTs, monocarboxylate transporters (MCTs) and excitatory amino acid transporters (EAATs), facilitate the transport of energy equivalents across membranes of diverse cell types that build up the central nervous system (CNS) $[9,15,16]$. Although glucose represents the most important energy substrate [9,17-19] a growing number of studies suggested that besides glucose oxidation lactate may also represent an important substrate to provide energy to brain cells $[18,20,21]$. The transport and utilization of lactate is based on the "astrocyte-neuron lactate shuttle hypothesis" and has already been proposed as a central energy providing pathway in the mammalian CNS $[9,22]$. Lactate is transported from astrocytes to neurons through MCT1 and 4 [23] and is converted to pyruvate by LDH1. Subsequently pyruvate dehydrogenase (E1) catalyzes the transformation of pyruvate to acetyl-CoA and enters the Krebs cycle to produce ATPs to fuel the energetic demands of neuron cells [24-27]. In this context special attention has been dedicated to monocarboxylate transporters (MCTs) that enable the transport of lactate in the mammalian brain $[9,22,28,29]$. MCTs belong to the solute carrier family (SLC) 16, which consists of 14 members in mammals [30-33]. Only MCT1, MCT2, MCT3 and MCT4 have been demonstrated to be responsible for the trans-membrane transport of relevant monocarboxylic acids, such as lactate, pyruvate and ketone bodies $[31,33,34]$. In mammals, MCT1 can be found in membranes of neurons and astrocytes of the CNS [31]. MCT1 was also detected in the sarcolemma of oxidative skeletal muscle fibers and cardiomyocytes, but never in fast-twitch glycolytic skeletal muscle fibers [35-37]. The lactate transport mechanism of MCT1 has been thoroughly studied [38,39]. MCT1 binds one proton and undergoes a conformational change, which transports the lactate molecule across the membrane [40-42]. Another paralogue, MCT2 has been demonstrated to be the major player for monocarboxylate transport in rodent brain neurons [17,43-45]. Overexpression of MCT2 in Xenopus oocytes revealed that this protein is also driven by proton fluxes and has a higher affinity for monocarboxylates than MCT1. The high affinity of MCT2 for monocarboxylates makes it especially suitable for transporting lactate into neurons for oxidation as an important energy source [46]. Moreover, MCT3 has a unique distribution in the basal membrane of retinal pigment epithelium and choroid plexus epithelia of mammals, but the detailed characterization of the transport kinetics have not been studied so far $[47,48]$. MCT4 has been reported to be localized in astrocytes, fast-twitch oxidative glycolytic skeletal muscle fibers and cardiomyocytes $[35,46]$. The lactate affinity of MCT4 is lower than that of MCT1 and MCT2, but MCT4 has a high capacity for lactate transport $[46,49,50]$. In summary, MCTs play an important role in the trafficking of lactate into energy-consuming cells to meet their energetic demands. Regarding lactate utilization in brains of teleosts, Polakof and colleagues [51,52] have demonstrated that lactate can act as an alternative energy fuel in glucosesensing brain regions such as hypothalamus and hindbrain. Thus, in ectothermic fish brain, lactate may have a similar metabolic role in maintaining energy homeostasis as observed in mammals [52,53]. However, the cellular mechanistic basis for lactate utilization and transport in brain of ectothermic animals are largely unexplored and may significantly differ from those described for mammalian systems. Zebrafish (Danio rerio) has been recently explored as a suitable model organism to study the effects of environmental stressors including hypothermic stress on various physiological processes [1,54-56]. Therefore, we use this ectothermic model species to study lactate utilization strategies and further demonstrate the role of MCTs in energy metabolism of brain under acute cold stress. First, we investigated the effect of cold acclimation 
on several metabolic indexes $\left(\mathrm{O}_{2}\right.$ consumption and $\mathrm{NH}_{4}^{+}$ excretion), carbohydrate contents and relevant metabolites enzymes to clarify if cold stress induced changes in metabolism are associated to enhanced lactate utilization. Based on our previous study that identified drMCT2 as an indispensable monocarboxylate-transporting route for brain development and function in zebrafish [57]. In order to extend our knowledge regarding differential functions of MCT isoforms in fish during cold-acclimation we identified and characterized additional teleost-specific isoforms. We hypothesize an evolutionary trend for diversified functions and dynamic expression patterns of MCT isoforms in the brain of ectothermic fish (Tseng et al. [57]). We further asked if drMCTs are involved in lactate utilization during cold acclimation and if drMCT isoforms play differential roles in this process. Accordingly, temperature-dependent lactate transport of MCT homologues' was characterized via expression and overexpression in Xenopus oocytes. These findings contribute to a better understanding for energy provision by monocarboxylate transport pathways during cold acclimation in brains of ectothermic vertebrates.

\section{Results}

Routine metabolic rates under acute cold exposure

Oxygen consumption rates were examined in zebrafish (body length: 4.0-4.5 cm) acclimated to control temperatures $\left(28^{\circ} \mathrm{C}\right)$ and those directly transferred to $18^{\circ} \mathrm{C}$ for 1 and $24 \mathrm{~h}$. As shown in Figure 1A, oxygen consumption rates of adult zebrafish exposed to $18^{\circ} \mathrm{C}$ for 1 and $24 \mathrm{~h}$ were about 2 - and 6-fold lower than those determined for control animals kept at $28^{\circ} \mathrm{C} . \mathrm{NH}_{4}^{+}$excretion rates significantly decreased in animals exposed to hypothermic stress (Figure 1B). After $24 \mathrm{~h}$ experimental period, $\mathrm{NH}_{4}^{+}$ excretion rates in $28^{\circ} \mathrm{C}$ acclimated fish was about 4 folds higher than in the hypothermic group.

\section{Glucose and lactate concentrations in zebrafish brain under acute hypothermic stress}

At $28^{\circ} \mathrm{C}$ glucose content in zebrafish brain was $0.43 \pm$ $0.08 \mathrm{nmole} / \mathrm{mg}$. No significant differences in brain glucose contents were observed between the animals from the $28^{\circ} \mathrm{C}$ group and the acute cold exposure group after $1 \mathrm{~h}(0.33 \pm 0.15 \mathrm{nmole} / \mathrm{mg})$ as well as the $24 \mathrm{~h}(0.68 \pm$ $0.45 \mathrm{nmole} / \mathrm{mg}$ ) group (Figure 2A).

Lactate levels in brain of zebrafish kept at $28^{\circ} \mathrm{C}$ was $48.33 \pm 7.48 \mathrm{nmole} / \mathrm{mg}$. In comparison to control $\left(28^{\circ} \mathrm{C}\right)$ animals, lactate contents in zebrafish brains which were exposed to $18^{\circ} \mathrm{C}$ for 1 and $24 \mathrm{~h}$ were decreased to $26.66 \pm$ 2.48 and $25.36 \pm 1.95 \mathrm{nmole} / \mathrm{mg}$, respectively (Figure $2 \mathrm{~B}$ ). This indicates a $45 \%$ to $49 \%$ decrease in brain lactate contents during 1 and $24 \mathrm{~h} 18^{\circ} \mathrm{C}$ exposure compared to control animals.
A
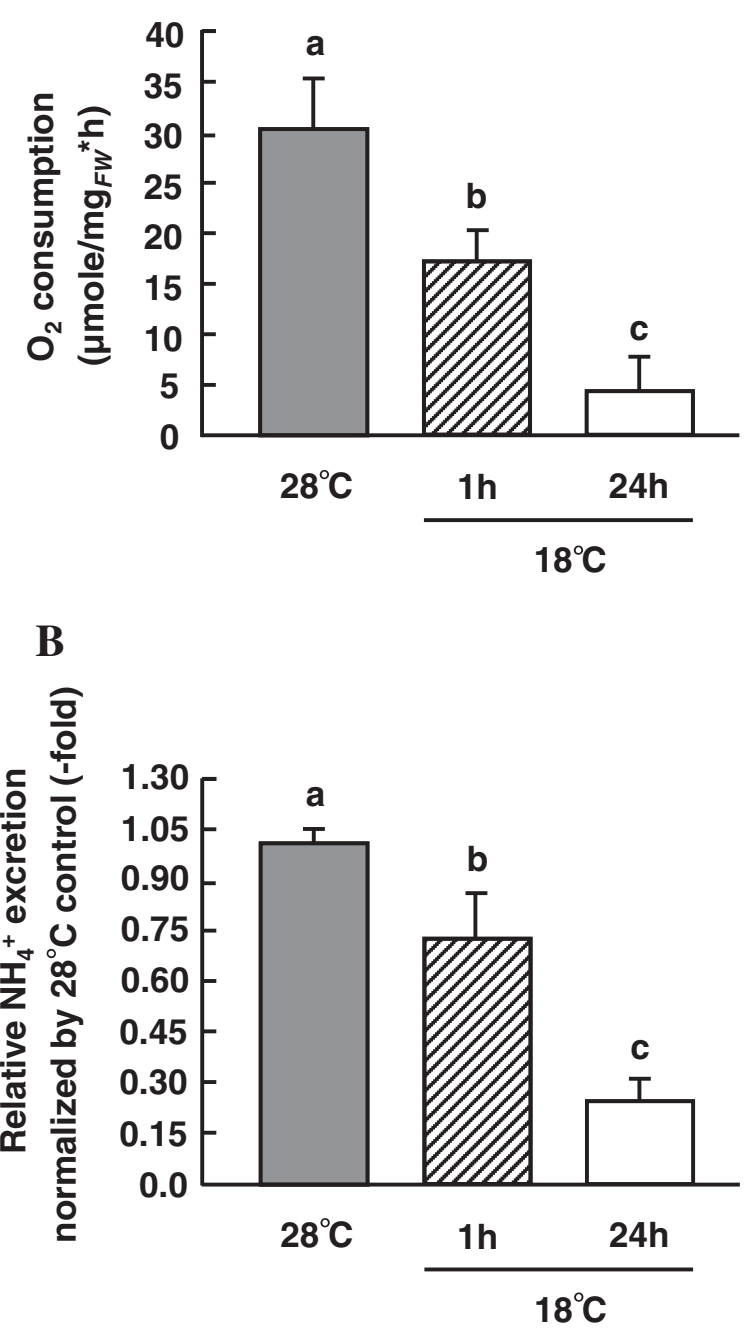

Figure 1 Routine intact oxygen consumption and $\mathrm{NH}_{4}^{+}$ excretion rates in adult zebrafish. Intact oxygen consumption (A) and $\mathrm{NH}_{4}^{+}$excretion rates (B) of adult zebrafish were determined after $1 \mathrm{~h}$ and $24 \mathrm{~h}$ exposure to $18^{\circ} \mathrm{C}$ cold conditions. Data are present as mean $\pm S D(n=10-12)$. Different letters indicate significant differences between treatments (One-way ANOVA, Tukey's pairwise comparisons, $p<0.05$ ).

Protein concentration and transcript abundance of metabolic genes during hypothermic stress

LDH1 protein concentrations were found to be increased 1.8-fold at the $24 \mathrm{~h}$ time point after exposure to $18^{\circ} \mathrm{C}$ (Figure 3A). In response to cold exposure for $24 \mathrm{~h}$, the relative protein level of citrate synthase (CS) was 2.5-fold higher compared to control conditions (Figure 3B). Gene expression analyses demonstrated that among the three pyruvate dehydrogenase phosphatase (PDP) paralogues expressed in zebrafish brain, $d r p d p 1 b$ is expressed 1 to 2-fold higher than the other two isoforms (Figure 4A-C). 


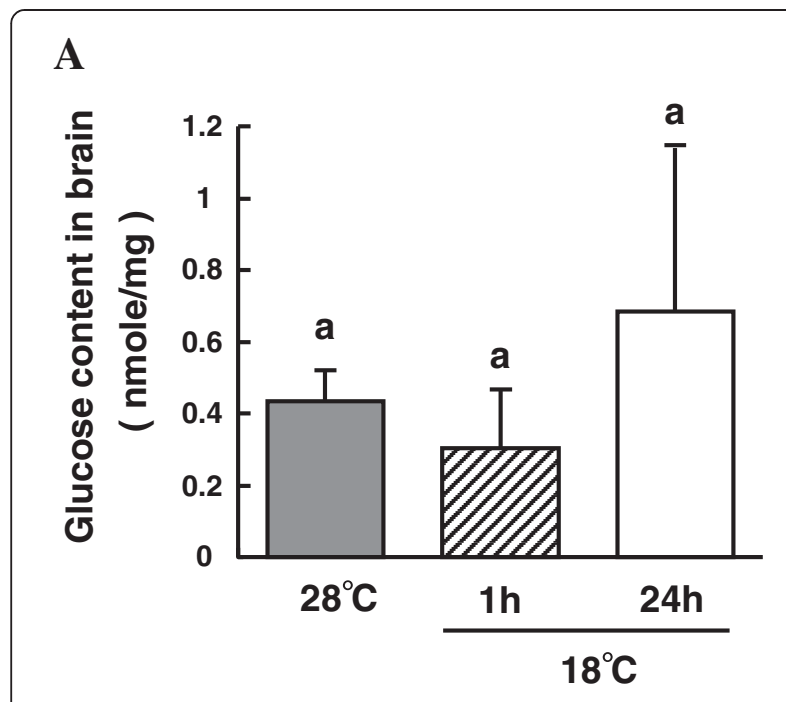

B

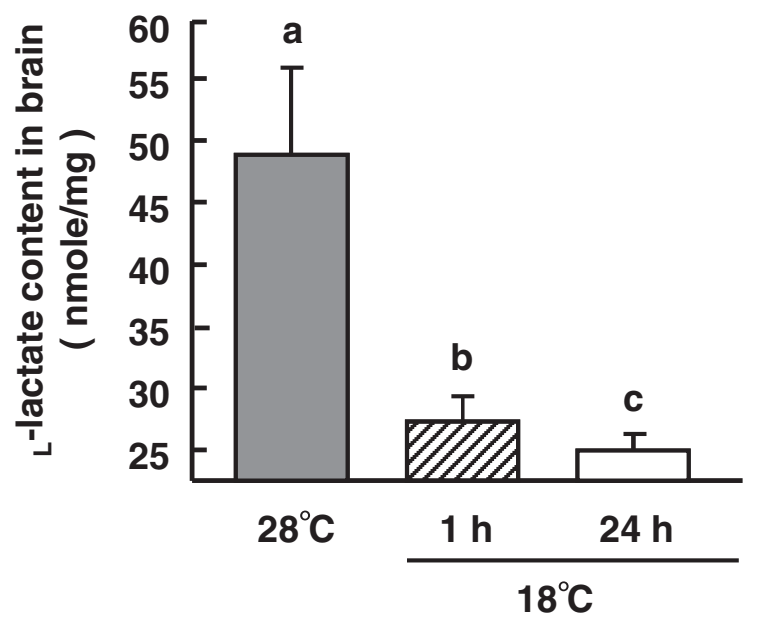

Figure 2 Time-course changes of glucose and L-lactate contents in zebrafish brain during $18^{\circ} \mathrm{C}$ treatment. Contents of glucose (A) and Llactate (B) were measured during $18^{\circ} \mathrm{C}$ cold treatment in brains of zebrafish. Data are present as mean $\pm S D(n=10-12)$. Different letters indicate significant differences $(p<0.05)$ between treatments (One-way ANOVA, Tukey's pairwise comparisons, $p<0.05$ ).

Within the first hour of acute $18^{\circ} \mathrm{C}$ cold shock only the drpdp $1 b$ increased significantly by about $27 \%(p<0.05)$ (Figure 4B). After $18^{\circ} \mathrm{C}$ cold exposure for $24 \mathrm{~h}$, drpdp $1 b$ and $d r p d p 2$ were up-regulated by about $80 \%$ and $52 \%$, respectively (Figure 4B and C). In addition, pyruvate kinase (PK) was also found to be expressed in zebrafish brain and transcript abundance of both, drpkma and drpkmb were not affected by ambient hypothermic exposure after $24 \mathrm{~h}$ (Figure 4D and E). However, transcript abundance of drpkma was decreased by about $39 \%$ in response to acute $(1 \mathrm{~h})$ cold exposure compared to control groups (Figure 4E).
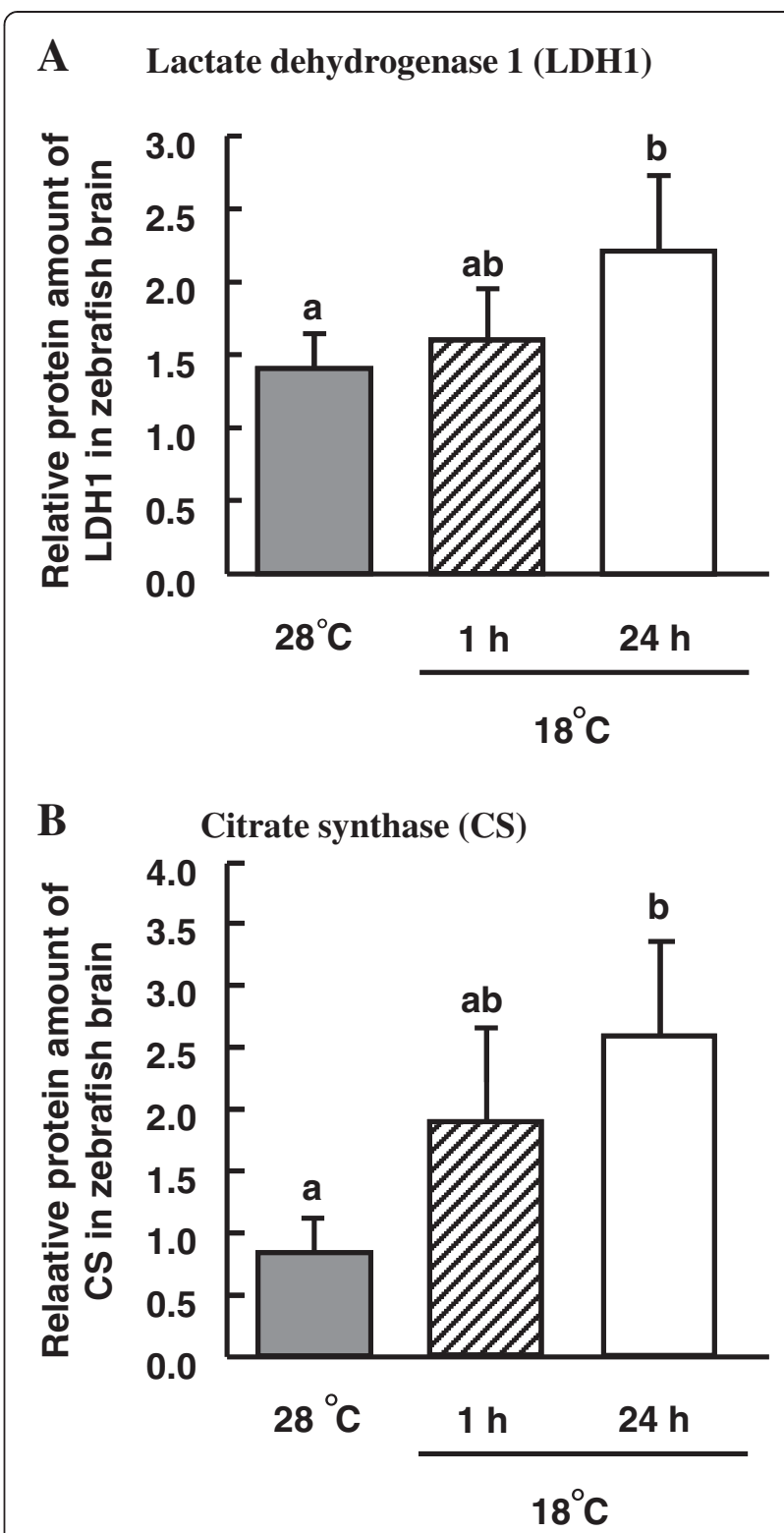

Figure 3 Time-course changes of lactate dehydrogenase 1 (LDH1) and citrate synthase (CS) relative protein amounts in zebrafish brain during $18^{\circ} \mathrm{C}$ treatment. Relative protein amounts of $\mathrm{LDH} 1$ (A) and $\mathrm{CS}$ (B) were measured during $18^{\circ} \mathrm{C}$ cold treatment in brains of zebrafish. Data are present as mean $\pm \operatorname{SD}(n=6)$. Different letters indicate significant differences $(p<0.05)$ between treatments (One-way ANOVA, Tukey's pairwise comparisons, $p<0.05)$.

\section{Identification of drMCTs in zebrafish}

In the present study, seven isoforms of MCTs $1 \sim 4$ were cloned and sequenced from zebrafish. There were two drMCT1 isoforms including drMCT1a (annotated as zMCT1 in the previous study) and drMCT1b; two drMCT2 isoforms including drMCT2a (annotated as zMCT2 in the previous study) and drMCT2b; one drMCT3 (annotated as zMCT3 in the previous study); 


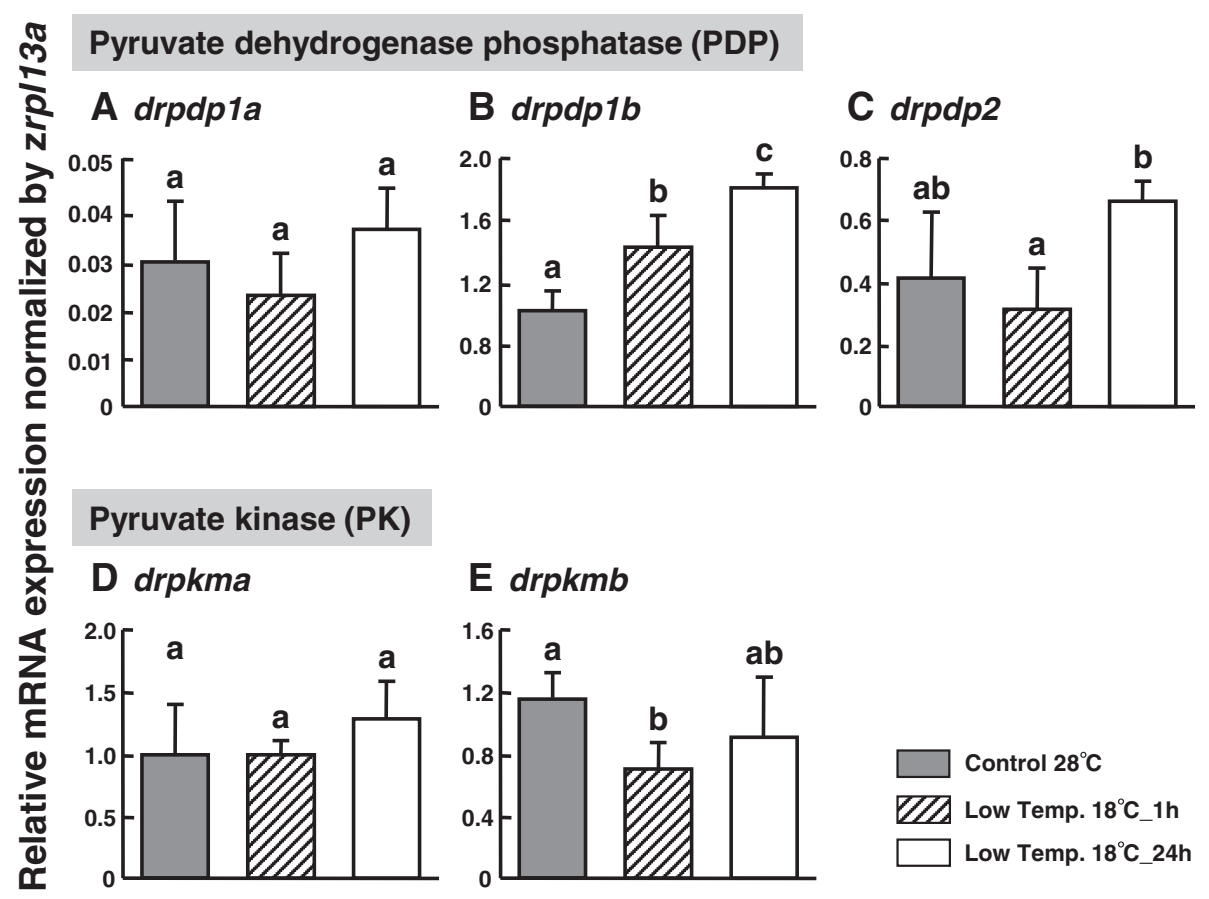

Figure 4 Time-course changes of pyruvate dehydrogenase phosphatase (PDP) and pyruvate kinase (PK) transcripts levels in zebrafish brain during $18^{\circ} \mathrm{C}$ treatment. Transcripts expression levels of PDP $(\mathbf{A}-\mathbf{C})$ and PK (D, E) were examined during $18^{\circ} \mathrm{C}$ cold treatment in brains of zebrafish. Expressions of the gene candidates were normalized to ribosomal protein L13A (drrp/13a) and presented as relative change. Data are present as mean \pm SD $(n=6)$. Different letters indicate significant differences $(p<0.05)$ between treatments (One-way ANOVA, Tukey's pairwise comparisons, $p<0.05)$. Gray panels: $28^{\circ} \mathrm{C}$ control; striped panels: $18^{\circ} \mathrm{C}$ treatment for $1 \mathrm{~h}$; white panels: $18^{\circ} \mathrm{C}$ treatment for $24 \mathrm{~h}$.

and two drMCT4 including drMCT4a (annotated as zMCT4 in the previous study) and drMCT4b. Neighbor joining (NJ) analysis was used to generate the phylogenetic tree of full-length amino acid sequences of MCT1 (SLC16A1), MCT2 (SLC16A7), MCT3 (SLC16A8) and MCT4 (SLC16A3) from human, mouse, chicken, frog, zebrafish and other teleosts. The phylogenetic analysis demonstrates that seven drMCT isoforms were clearly classified into different groups and clustered with orthologues from other species (Figure 5).

In order to characterize the physicochemical properties of drMCTs, protein trans-membrane predictions were generated (Figure 6). The analysis demonstrates that drMCT $1 \mathrm{a},-1 \mathrm{~b}$ and $-2 \mathrm{a}$ have 11 putative trans-membrane domains (TMDs) with extracellular N-termini and cytoplasmic C-termini (Figure 6A-C) whereas drMCT2b, -3, -4a and $-4 \mathrm{~b}$ have 12 putative TMDs with cytoplasmic $\mathrm{C}$ - and $\mathrm{N}$-termini (Figure 6D-G). Based on this analysis, a large cytoplasmic loop (30-53 AA) between TMDs 6 and 7 was found in drMCT2b, -3, $-4 a$ and $-4 b$ (Figure 7). Moreover, drMCT1a, $-1 \mathrm{~b}$ and $-2 \mathrm{a}$ can be characterized by a large cytoplasmic loop (41-44 AA) between TMDs 5 and 6 and an additional extracellular loop consisting of about 20-30 AA between TMDs 2 and 3 (Figure 6).

\section{Expression of drMCTs in brains of zebrafish}

35 cycles amplification of RT-PCR analysis for various MCTs was conducted in different tissues including brain, gill, eye, spleen and liver from adult zebrafish. Except from $d r m c t 1 b$ and $-4 b$ which were not detected in liver, drmct1a, $-2 a,-2 b,-3$ and $-4 a$ were ubiquitously expressed in various tissues of zebrafish. All the transcripts of drmct1-4 paralogues were detected in brain tissues (Figure 7A).

Based on our previous studies, spatial expressions of drmct $1 a,-2 a,-3$ and $-4 a$ mRNAs in brains of adult zebrafish were already proved to be expressed in both neurons and astrocytes [57]. To further identify cell types that express three novel drMCT1b, $-2 \mathrm{~b}$ and $-4 \mathrm{~b}$, in vitro synthesized RNA probes were used to detect mRNA of these paralogues in transverse sections of zebrafish brains hypothalamus. Subsequent immunocytochemical labeling with ZN12 and glial fibrillary acidic protein (GFAP) antibodies was carried out to specifically identify neurons and astrocytes, respectively [58,59]. In our preliminary test, ZN12 and GFAP were shown to specifically characterize neurons and astrocytes, respectively, in the midbrain of zebrafish [57]. On one hand as shown in Figure $7 \mathrm{~B}$ and $\mathrm{C}$, drmct1b and $-2 b$ (fluorescence in situ hybridization) were both detected in specified groups of 


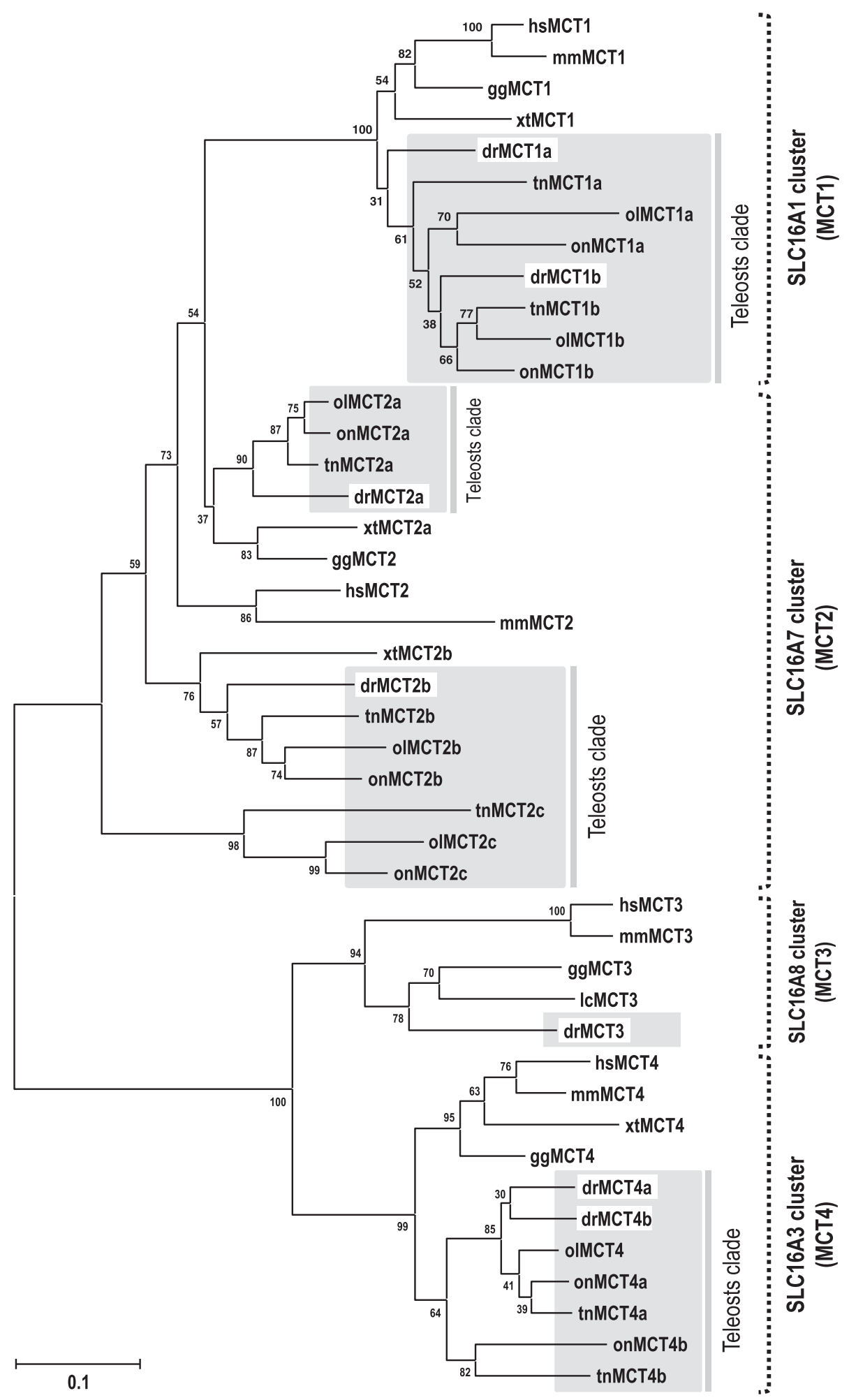

Figure 5 Routed phylogenetic analysis of the MCT1-4 amino acid sequences. The putative MCT sequences of other species were obtained from the Ensembl database, as shown in Table 2. Consensus trees were generated using the Neighbor-joining method with the pairwise deletion gap calculating option. The results were confirmed by 10,000 bootstraps. Numbers indicate bootstrap values and the scale bar units are the number of amino acid substitutions per site. 


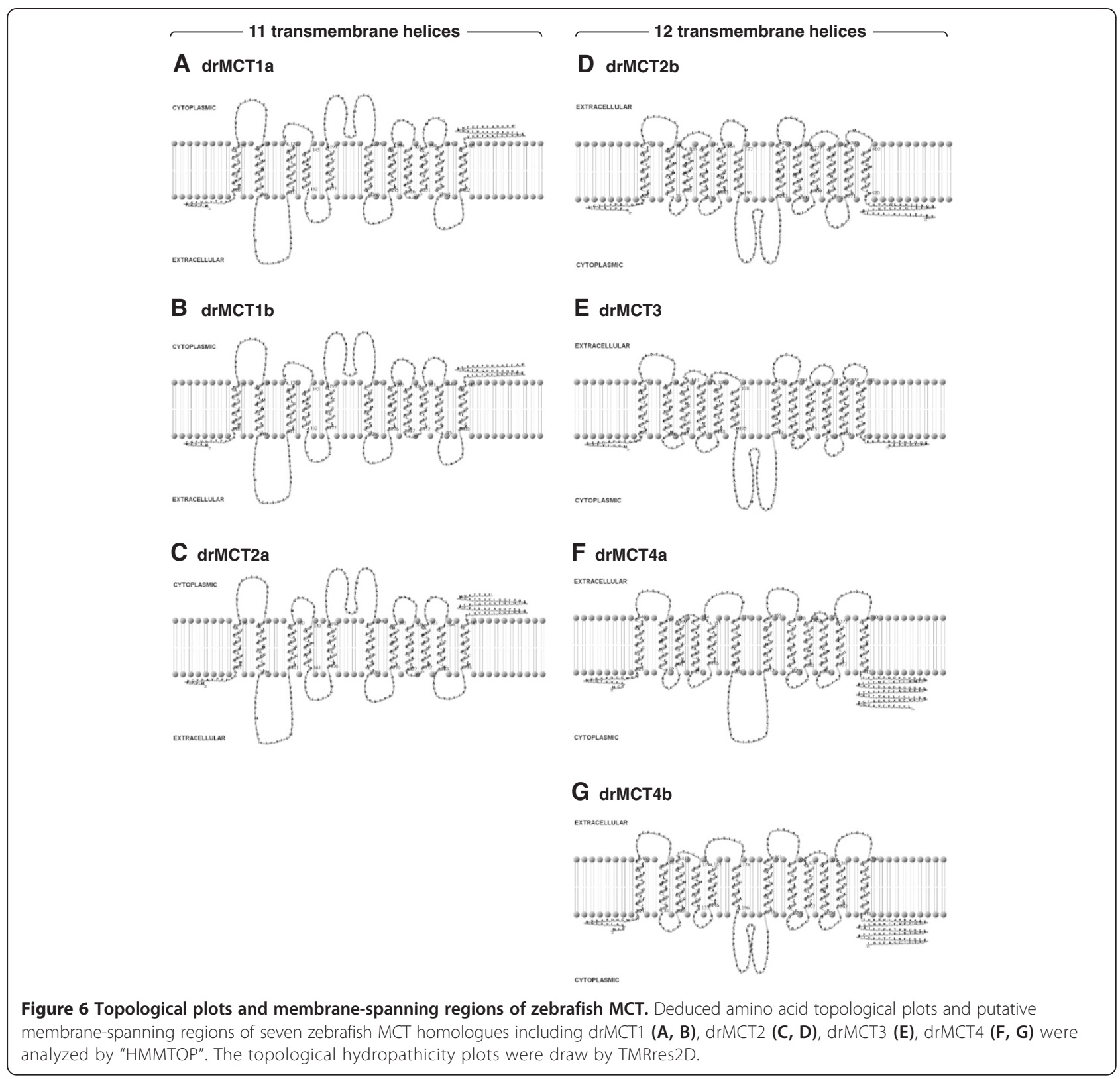

brain cells, which were recognized as neuron cells with the ZN12 antibody but never co-localized with GFAP signals. On the other hand, drmct $4 b$ was detected in both ZN12 and GFAP recognized brain cells (Figure 7D). Therefore, these images indicated that drmct $4 b$ was expressed in both neurons and astrocytes.

Figure 8 shows the time-course changes of drmct1-4 mRNA expression levels in zebrafish brain in response to acute transfer from $28^{\circ} \mathrm{C}$ to $18^{\circ} \mathrm{C}$ with drrpl13a serving as an internal control. Furthermore, the results are presented relative to $d r m c t 2 b$. In zebrafish brain, on one hand, the mRNA expression of drmct1b, drmct4a and drmct $4 b$ were 60 to 400 -fold higher compared to expression levels of other paralogues. On the other hand, drmct $2 b$ and drmct 3 expression levels were comparatively lower than those of other paralogues. After $18^{\circ} \mathrm{C}$ exposure for $24 \mathrm{~h}$, mRNA expression of $\operatorname{drmct} 2 a$ and drmct4a transcripts in brain tissues were upregulated by 5 - and 3 -fold, respectively (Figure $8 \mathrm{C}$ and F). On the contrary, transcript levels of drmct1a, drmct $1 b$ and drmct4b in zebrafish brain were decreased after $1 \mathrm{~h}$ exposure to cold stress by about 33\%, $81 \%$ and $62 \%$, respectively (Figure $8 \mathrm{~A}, \mathrm{~B}$ and G). However, after exposure to $18^{\circ} \mathrm{C}$ for $24 \mathrm{~h}$, drmct $1 b$ and drmct $4 b$ mRNA levels in brain tissues were still decreased by about $90 \%$ and $58 \%$, respectively, compared to the 


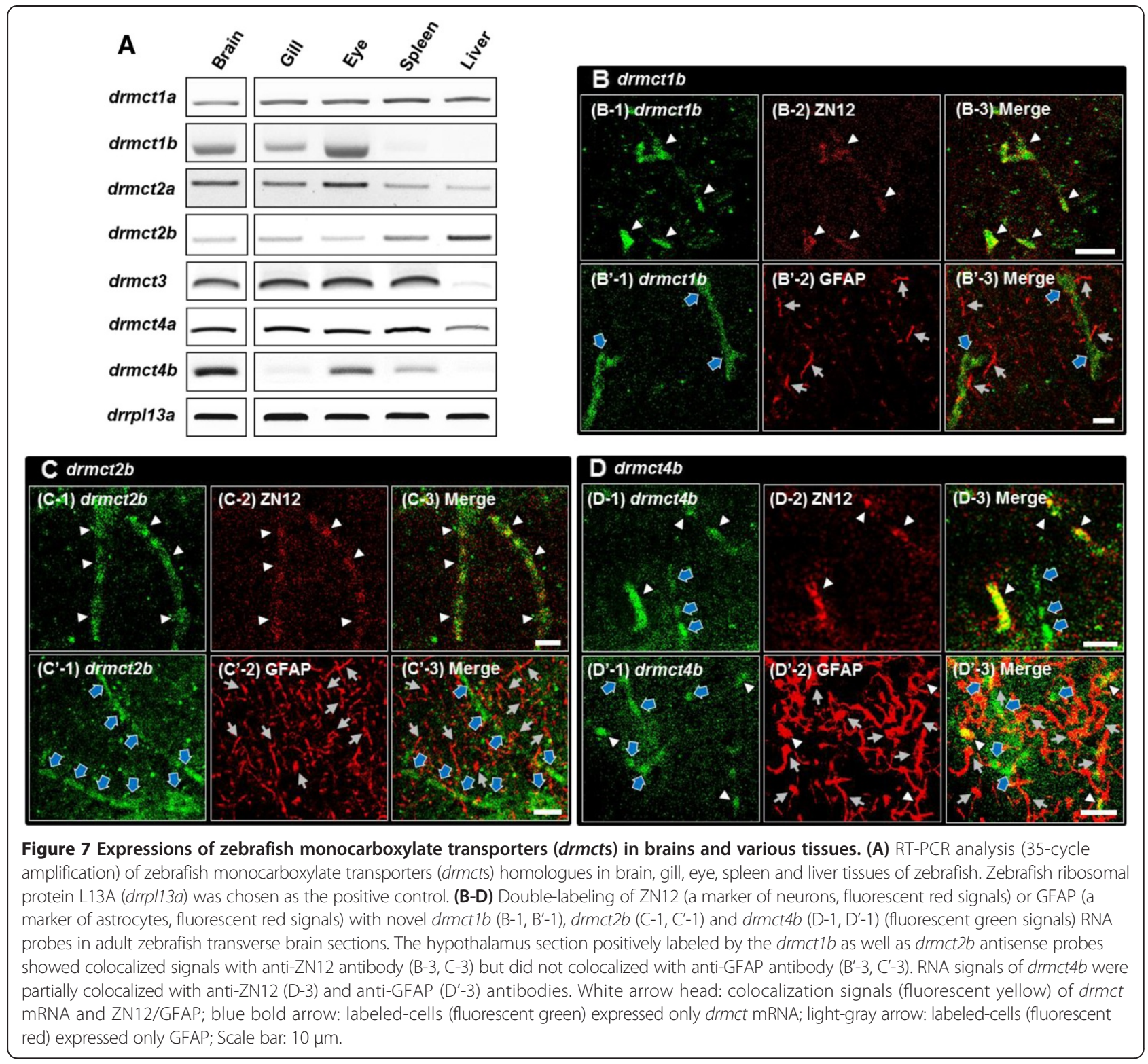

control group (Figure 8B and G). Compared to other paralogues, $d r m c t 2 b$ and $d r m c t 3$ mRNA levels maintained stable during the entire cold-shock period (Figure 8D and E).

\section{In vitro functional analysis of drMCTs in Xenopus laevis oocytes}

Using functional expression of drMCTs in oocytes we determined $\mathrm{L}_{\mathrm{L}}$-lactate uptake by measuring the accumulation of ${ }^{14} \mathrm{C}$-labeled ${ }_{\mathrm{L}}$-lactate during exposure to $28^{\circ} \mathrm{C}$ and $18^{\circ} \mathrm{C}$ (Figure 9). Two days after injection, the rate of lactate uptake was $1.3 \sim 4.1$-fold higher in oocytes injected with drMCTs' cRNA, compared to control oocytes (RNase-free MBS injection). The rate of lactate uptake by drMCT1b expressing oocytes was highest
( 1200 nmole/hr"oocyte) compared to oocytes expressing other paralogues at $28^{\circ} \mathrm{C}$, while the highest uptake rates ( 1700 nmole/hr"oocyte) were measured in drMCT4b expressing oocytes at $18^{\circ} \mathrm{C}$ (Figure 9). In addition, the amount of lactate transported by oocytes expressing drMCT2a was significantly decreased by approximately $73 \%$ at $18^{\circ} \mathrm{C}$ compared to those measured at $28^{\circ} \mathrm{C}$; in contrast, lactate transport abilities of drMCT4b expressing oocytes was increased up to 2 -fold at $18^{\circ} \mathrm{C}$. Besides drMCT2a and drMCT4b, in vitro examination in Xenopus oocytes revealed that ${ }_{\mathrm{L}}$-lactate transport characteristics of other drMCT paralogues were not significantly affected by ambient temperature.

Kinetic analyses of ${ }_{\mathrm{L}}$-lactate transport at $28^{\circ} \mathrm{C}$ and $18^{\circ} \mathrm{C}$ in drMCT2a- and drMCT4b-injected oocytes are shown 


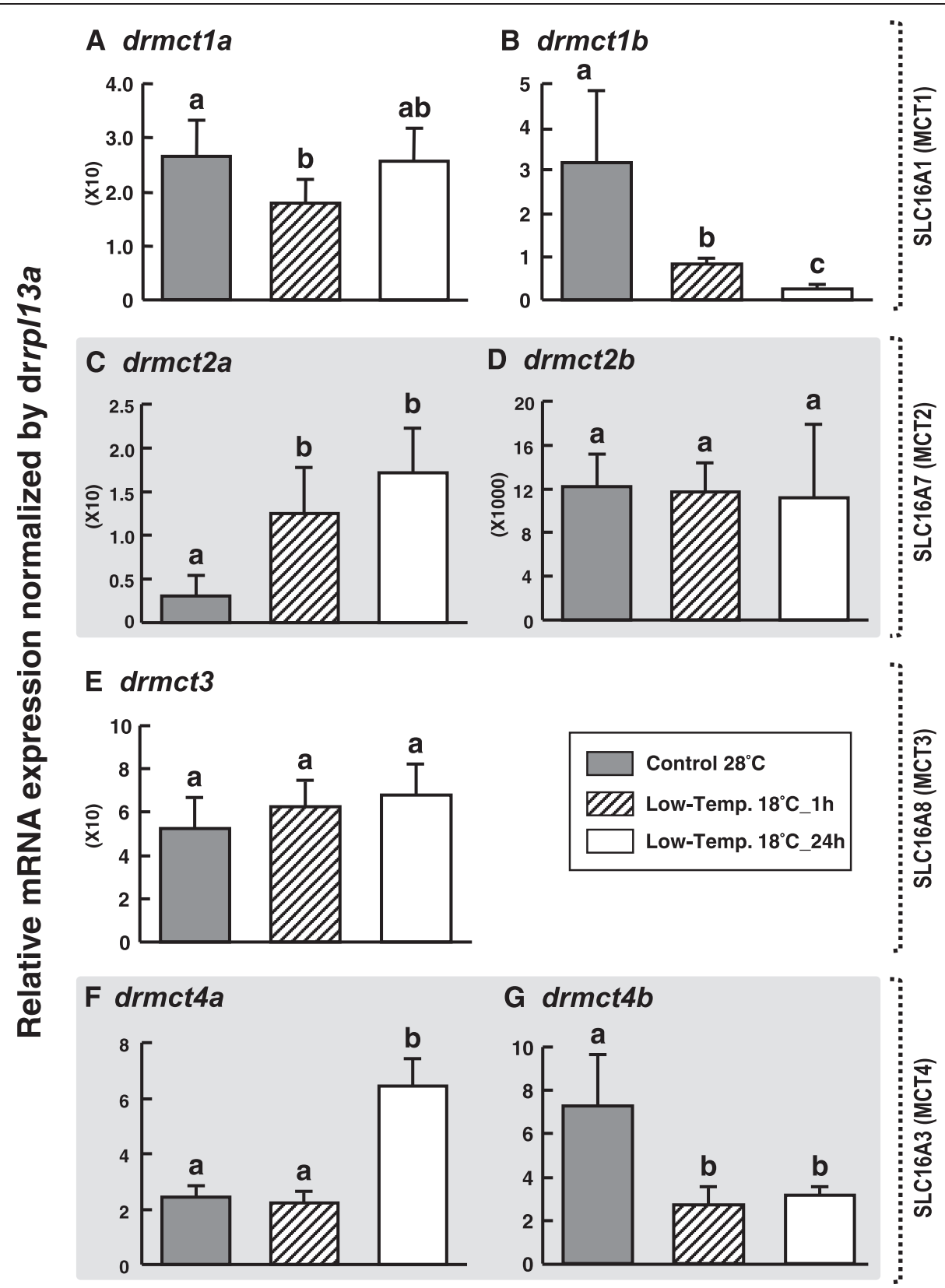

Figure 8 Time-course changes of zebrafish monocarboxylate transporters (drmcts) transcripts levels in brain during $18^{\circ} \mathrm{C}$ treatment. Quantitative real-time PCR (qRT-PCR) were utilized to compare drmcts mRNA expressions in brains between $28^{\circ} \mathrm{C}$ control group and $18^{\circ} \mathrm{C}$ cold treatment counterparts. Zebrafish ribosomal protein L13A (drrp/13a) was used as an internal control. Values are presented as the mean \pm SD $(n=6)$. Different letters indicate significant differences between treatments. (One-way ANOVA, Tukey's pairwise comparisons, $p<0.05)$. Gray panels: $28^{\circ} \mathrm{C}$ control; striped panels: $18^{\circ} \mathrm{C}$ treatment for $1 \mathrm{~h}$; white panels: $18^{\circ} \mathrm{C}$ treatment for $24 \mathrm{~h}$.

in Figure 10. After exposure to $18^{\circ} \mathrm{C}$ for $0.5 \mathrm{~h}$, lactate transport activity by drMCT2a was 8 -fold less than in the $28^{\circ} \mathrm{C}$ treatment group. After $2 \mathrm{~h}$ lactate transport ability of drMCT2a-injected oocytes at $18^{\circ} \mathrm{C}$ was still about 6-fold lower than at $28^{\circ} \mathrm{C}$ (Figure 10A). Nevertheless, during $1 \mathrm{~h}$ exposure to $18^{\circ} \mathrm{C}_{\mathrm{L}}$-lactate transport ability of drMCT4binjected oocytes was observed to be maintained at about 2.3fold higher levels compared to the $28^{\circ} \mathrm{C}$ control counterpart.

\section{Discussion}

The present work demonstrated that lactate utilization in zebrafish brain represents an advantageous feature to adequately and timely provide energy in brain tissues during acute (1- and $24 \mathrm{~h}$ ) cold exposure. Furthermore, drMCT isoforms expressed in oocytes reveal differential characteristics in terms of temperature-dependent lactate transport. The lactate uptake of drMCT2a expressing 


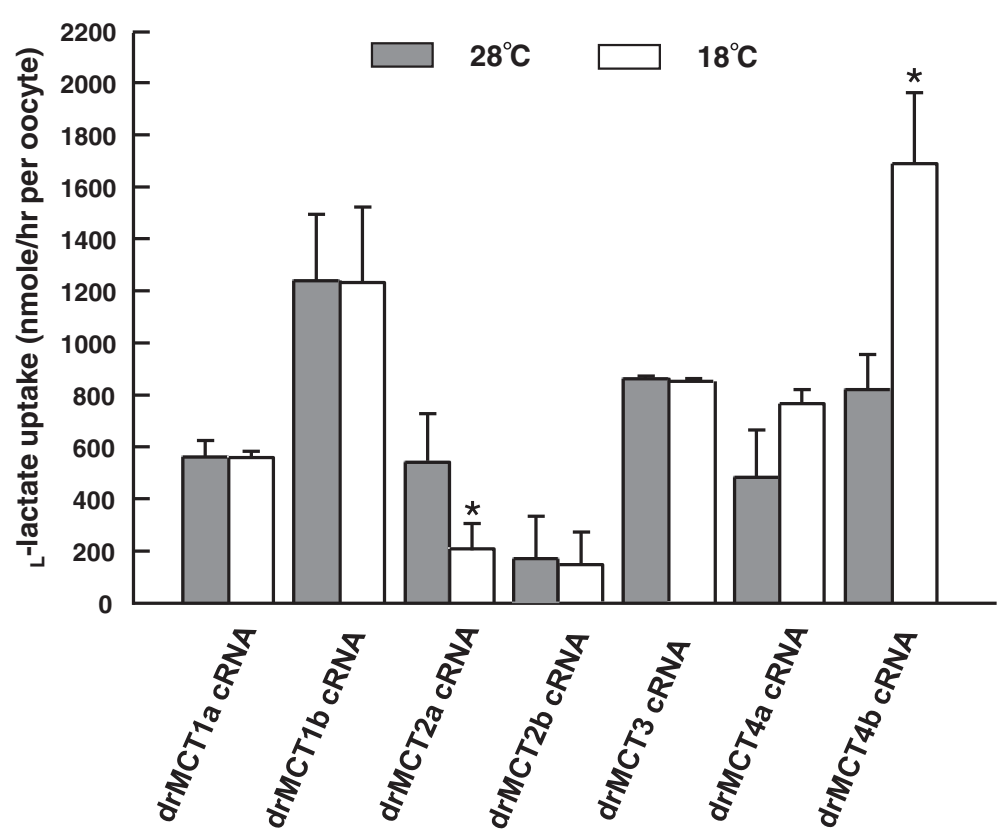

Figure 9 Functional analysis of drmct homologues in Xenopus oocytes. After the injection of $5 \mathrm{ng}$ drmcts cRNA into Stage V-VI Xenopus oocytes for 2 days, the uptake experiment was initiated by transferring the oocytes to $28^{\circ} \mathrm{C}$ or $18^{\circ} \mathrm{C}$ for $6 \mathrm{~h}$ and then $L^{-}\left[{ }^{14} \mathrm{C}\right]-$ lactate $(5 \mathrm{kBq})$ was added into the incubation medium. Data are present as mean \pm SD $(n=20)$. Different letters indicate significant differences between treatments (One-way ANOVA, Tukey's pairwise comparisons). * , Significantly different between $28^{\circ} \mathrm{C}$ and $18^{\circ} \mathrm{C}$ (Student's t-test, $p<0.05$ ).

oocytes was decreased while those expressing drMCT4b were stimulated by low temperature $\left(18^{\circ} \mathrm{C}\right)$. These findings, relevant for brain functionality during cold stress are discussed in the following and embedded in the existing body of knowledge.

In the present study, oxygen consumption rates of adult zebrafish transferred from $28^{\circ} \mathrm{C}$ to $18^{\circ} \mathrm{C}$ for 1 and $24 \mathrm{~h}$ were 2 - to 6 -fold decreased, indicating that acute hypothermic stress directly translates into decreased metabolic rates on the whole animal level. On one hand, hypothermic challenges may directly affect metabolic enzyme activities and muscle contraction; on the other hand, cold-induced activation of the neuroendocrine system (e.g. TRH release) may be beneficial to counteract physiological compromises during hypothermic stress [60]. Similar observations were made for a range of other fish species with $Q_{10}$ values between 2 and 3 although $Q_{10}$ may show strong differences between species and ontogenetic stages [61-64]. The fact that $Q_{10}$ increased further in response to $24 \mathrm{~h}$ cold acclimation is in accordance to $Q_{10}$ values determined for adult zebrafish which are typically in the range between 4-6 [65]. Therefore it can be expected that the highly energy consuming vertebrate brain $[1,9,10]$ is exposed to acute energy fluctuations as well. Thus it is interesting and important to understand how brain energy metabolism of ectotherms is regulated under hypothermic stress. Previous studies demonstrated that Antarctic fish have higher lactate dehydrogenase (LDH) and citrate synthase (CS) activity in brain tissues compared to tropical and subtropical fishes [6,7]. This suggests that despite comparatively lower metabolic rates and depressed enzymatic activities in locomotory muscle of cold adapted fish, the energy providing pathways that fuel metabolic demands of the brain have to compensate for cold-dependent activity losses [6,8]. This ability is essential for brain functionality under hypothermic stress and allows fish to survive at low temperatures. On one hand, earlier studies indicated that fish can use lactate as an additional energy substrate during acclimation to severe environmental conditions including salinity and temperature changes $[8,66,67]$. On the other hand, lactate utilization is involved in glucose-sensing capacity and further allowed the maintenance of energy homeostasis in fish brain $[68,69]$. In the present study, a significant 2 -fold decrease, of brain lactate content was found in zebrafish brain transferred from $28^{\circ} \mathrm{C}$ to $18^{\circ} \mathrm{C}$ for 1 and $24 \mathrm{~h}$. This decrease of lactate concentrations may indicate enhanced lactate utilization from the lactate pool in fish brain under hypothermic conditions. Together with increased LDH protein concentrations we suggest that lactate is metabolized at higher rates in response to acute cold stress in brain tissues. Kawall and colleagues [6] also denoted that LDH activities in Antarctic fish brains were significant higher compared to those in tropical/subtropical fish species. Therefore lactate utilization and LDH activation for ATP production may represent a potential benefit for energy mobilization 


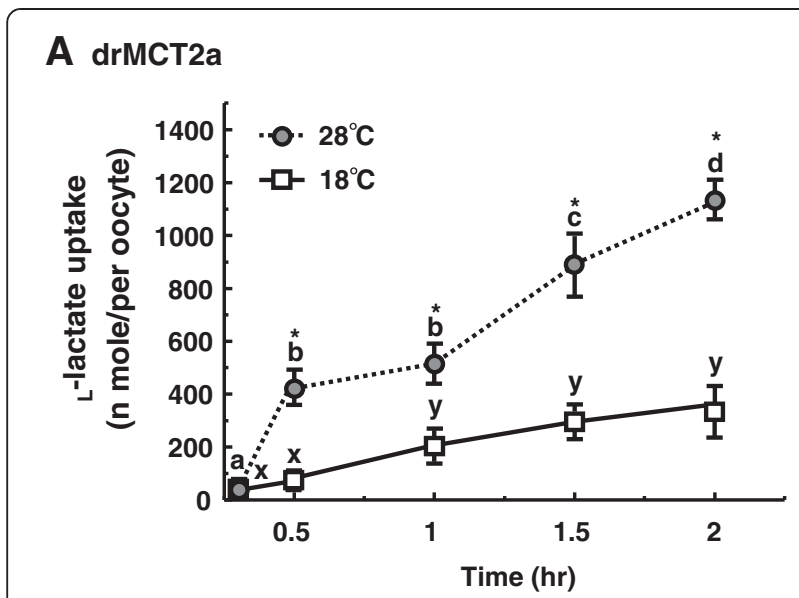

B drMCT4b

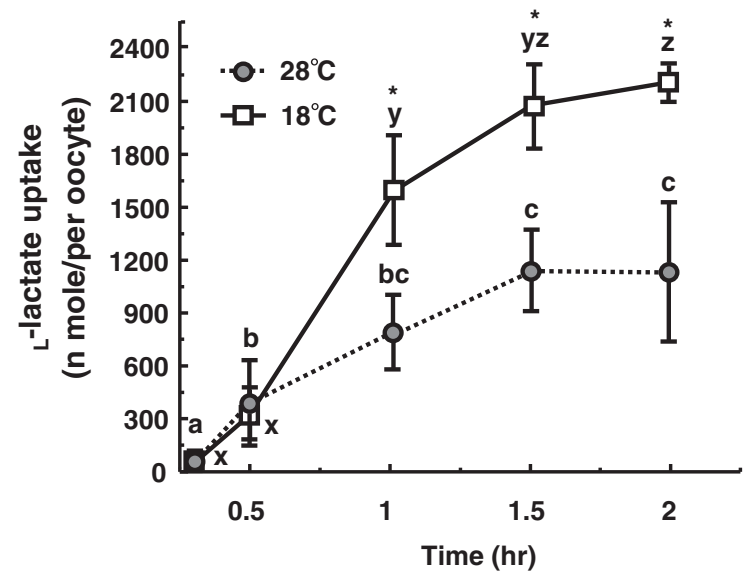

Figure 10 Time-course changes of $\mathrm{L}_{\mathrm{L}}\left[{ }^{14} \mathrm{C}\right]$-lactate uptake in drMCT2a and drMCT4b expressed Xenopus oocytes. Uptake of $\mathrm{L}^{-}\left[{ }^{14} \mathrm{C}\right]$-lactate $(5 \mathrm{kBq})$ at $28^{\circ} \mathrm{C}$ and $18^{\circ} \mathrm{C}$ conditions were measured 2 days after the injection of drMCT2a (A) and drMCT4b (B) CRNA into stage $\mathrm{V}$-VI Xenopus oocytes. For each time point the mean uptake ability of 25-30 oocytes is shown. Different letters indicate significant differences between treatments (One-way ANOVA, Tukey's pairwise comparisons). ${ }^{*}$, Significantly different between $28^{\circ} \mathrm{C}$ and $18^{\circ} \mathrm{C}$ (Student's t-test, $p<0.05$ ).

in fish brain under hypothermic conditions. Moreover, increased protein levels of pace-determining metabolic enzymes involved in lactate metabolism and energy equivalent synthesis within the krebs cycle also support our hypothesis that lactate utilization is increased to control energy homeostasis in zebrafish brain during acute ( 1 and $24 \mathrm{~h}$ ) cold stress. Our results further suggest that the "lactate-shuttle hypothesis" model established in mammalian systems has also evolved in the teleost brain [57]. This hypothesis denotes that lactate formed in astrocytes is shuttled into neurons via MCTs as an alternative energy source. Thus, increased mRNA levels of PDP and PK particularly support this pathway because lactate transported into neurons needs to be converted to pyruvate and NADH. In the context of acclimation to cold stress, lactate may represent an important metabolite to support energy metabolism in fish brain. Ivanov and colleagues [70] demonstrated that lactate is an efficient energy substrate to fuel brain aerobic energy metabolism in case of insufficient glucose supply under intense synaptic activity. In this example LDH1 converts lactate to pyruvate and generates cellular NADH pools which represent an important physiological response to neural activation. This lactate metabolizing pathway has been suggested to be more beneficial for rapid energy supply compared to pyruvate formation via glycolysis [71]. Although lactate has long been considered as a potentially toxic metabolic waste product recent findings could demonstrate that neurons preferentially consume lactate as energy substrate using rat neuronal culture experiments $[28,72]$. In addition, lactate also evokes neuroprotective effects via transcriptional activation of brain-derived neurotrophic factor (BDNF), an essential factor for nerve cells survival [73]. Based on our acute hypothermic challenge in zebrafish, we provided convincing molecular evidences to prove that the astrocyte-neuron lactate shuttle hypothesis (ANLSH) that has been proposed in mammals and other teleosts is an important pathway in fish brain, as well. The existence of the lactate shuttle in fish brain mediated by MCTs further suggests that lactate may serve as an alternative metabolite in brain tissues [66]. Furthermore, transport of lactate between astrocytes and neurons via MCTs in ectothermic fish brain not only plays a critical role for glucosensing function [67], but is also beneficial for fish to cope with acute hypothermic stress.

In contrast to mammals, where only four MCT isoforms have been described, more additional paralogues have been found in teleosts. Some of these novel isoforms were demonstrated to mediate lactate cycling between cells in fish swim bladder [74]. In this study, three novel MCT isoforms, drMCT1b, $-2 b$ and $-4 b$, were explored and sequenced from zebrafish and most of them specifically clustered with those from other teleosts. Phylogenetic analysis inferred that diverse functionalities of MCT homologues could have evolved among teleosts and other higher vertebrates. Moreover according to the analysis of physicochemical properties, amino acid residues and membrane-spanning domains, all the drMCT paralogues were predicted to have a long C-terminus, and drMCT2b, $-3,-4 a$ and $-4 b$ have conventional features of 12 putative TMDs similar to MCT homologues of mammals [30,49]. Interestingly only 11 putative TMDs were predicted for drMCT1a, $-1 \mathrm{~b}$ and $-2 \mathrm{a}$ which differs from other homologues [75]. According to findings in mammalian MCT structural characterizations, the greatest sequence variation between different $\mathrm{MCT}$ 
isoforms has been observed in the large cytoplasmic loop between TMDs 6 and 7 [30]; therefore it would be interesting to investigate whether structural differences in TMD numbers or interval loop between TMDs can be related to differential lactate transport abilities of MCTs from ectothermic animals. To offer more definite conclusions regarding structural and functional characteristics of MCT isoforms deeper protein structural analysis such as protein chimera studies, nuclear magnetic resonance spectroscopic (NMRS) or X-ray spectroscopic investigations in combination with determinations of lactate transport rates are needed.

Based on our semi-quantitative PCR results, each organ tested expressed more than one MCT isoforms in zebrafish with all seven MCT isoforms detected in brain tissues. In mammals, MCT1 was expressed in most of tissues and sometimes in combination with other MCT isoforms [29-31]. However, compared to MCT1, a higher affinity for lactate and pyruvate was found for MCT2 in mammalian systems [31]. This paralogue is primarily expressed in liver, kidney, brain, sperm tail, skeletal muscle, and heart and has been described to transport significant amounts of lactate that can be used as energy source [76,77]. In zebrafish, drMCT2a (annotated as zMCT2 in the previous study) has been previously described as an essential component for the development of the central nervous system (CNS) by mediating monocarboxylate transport [57]. Compared with our previous study, the novel drmct $2 b$ orthologues were found to be specifically expressed in neurons while drmct2a was localized both in neuron and astrocyte [57] and expressed at higher rates than $\operatorname{drmct} 2 b$. MCT3 has a unique distribution in the basal membrane of the mouse choroid plexus epithelia [47]. Nevertheless in this study, drmct 3 was highly expressed in most examined tissues except for liver, different from the mammalian MCT3 which was expressed in retinal cells only $[30,47,48]$. However, the physiological role of MCT3 remains unclear in the mammalian homologue [31]. The fact that all the drMCT isoforms were expressed in different cell types of the zebrafish brain suggest that lactate transport between neuron and glial cells and its utilization are probably even more complex in ectothermic fish than in warm-blooded vertebrates.

In zebrafish brain, mRNA expressions of $d r m c t 1 b$ and drmct $4 a$ were about 10 -folds higher than that of drmct3, while $d r m c t 2 a$ and $d r m c t 2 b$ expression levels were comparatively lower than those of drmct3. This is different from findings in mammals where the expression level of MCT2 was higher than that of MCT1 in brain tissues [78]. Compared to other MCT homologues, expression of drmct $2 a$ transcripts in fish brain was up-regulated both at 1- and 24-h cold shock, while the transcript of drmct $4 a$ was only increased after $24 \mathrm{~h}$ hypothermic stress. In contrast $d r m c t 1 b /-2 b$ (specifically expressed in neurons) and drmct3/-4b (expressed both in neurons and astrocytes) mRNA levels in brain were down-regulated or remained unchanged during the acute cold-shock period. According to these differential and partly opposing expression patterns of drMCT isoforms in brain we hypothesize that during acute cold stress an increased lactate demand is mediated by a shift between different MCT isoforms. In order to provide a deeper insight regarding the differential functionality of MCT isoforms we conducted lactate uptake experiments using MCT expressing oocytes.

The present study demonstrated positive lactate uptake rates in all drMCT expressing oocytes with highest uptake rates for drMCT1b compared to all other paralogues. These findings are slightly differing from those obtained for mammals where only MCT1, -2 and -4 have been clearly demonstrated to transport lactate with different capacities $[29,30]$. Also in chicken, MCT3 has been demonstrated to transport lactate when expressed in a yeast cells [47]. Interestingly, an opposing response of drMCT2a and drMCT4b were observed under $18^{\circ} \mathrm{C}$ treatment. While lactate uptake of drMCT2a expressing oocytes was decreased ( 66\%), oocytes expressing drMCT4b increased lactate uptake 1.8-fold during exposure to $18^{\circ} \mathrm{C}$. This observation was further supported in vitro by higher lactate transport rates for drMCT4b and lower lactate uptake rates for drMCT2a under hypothermic conditions. The other drMCT paralogues remained unaffected by hypothermic conditions suggesting that transport characteristics of drMCT1a, $-1 b,-2 b,-3$ and $-4 a$ have a low thermal sensitivity. These observations could suggest that i) cold induced mRNA activation of $\operatorname{drmct} 2 a$ may serve compensatory processes for the decreased expression of drmct4b; ii) and/or increased transcript abundance of drmct $2 a$ is necessary to compensate for decreased transport rates under hypothermic conditions; iii) and/or a compensatory mechanism may also apply for drmct4b (the highest expression transcript in brain) where increased cold-induced lactate transport rates are balanced via down regulated mRNA synthesis for metabolic savings. The calculation of a theoretical total lactate transport by combining relative changes of in-vivo expression levels and in-vitro lactate transport between $28^{\circ}$ and $18^{\circ} \mathrm{C}$ indicates a stronger relative response for drMCT2a (2.20 fold-change) than for drMCT4b (0.86 fold-change) (Table 1$)$. These findings corroborate with our previous abrogation test demonstrating an essential role of drMCT2a in zebrafish CNS development [57]. However, drMCT4b has much higher lactate transport capacities and mRNA levels under control conditions compared to drMCT2a. This suggests a significant contribution to lactate transport in fish brain by drMCT4b, as well. The fact that this novel isoform is absent in mammals suggests that drMCT4b is teleost specific, and evolved 
Table 1 Comparison of the expression and function of drMCT2aand-4bunder acute cold exposure in zebrafish

\begin{tabular}{|c|c|c|c|c|c|c|}
\hline \multirow{3}{*}{ Average value } & \multicolumn{3}{|l|}{ drMCT2a } & \multicolumn{3}{|l|}{ drMCT4b } \\
\hline & $28^{\circ} \mathrm{C}$ & $18^{\circ} \mathrm{C}$ & Fold of change & $28^{\circ} \mathrm{C}$ & $18^{\circ} \mathrm{C}$ & Fold of change \\
\hline & (Control) & (for $24 \mathrm{~h}$ ) & & (Control) & (for $24 \mathrm{~h}$ ) & \\
\hline \multicolumn{7}{|l|}{ (A) } \\
\hline Relative expression (normalized by drrp/13a) & 0.03 & 0.17 & 5.67 & 7.4 & 3.1 & 0.41 \\
\hline \multicolumn{7}{|l|}{ (B) } \\
\hline Lactate uptake rate (n mole/h/oocyte) & 525.73 & 202.42 & 0.39 & 806.90 & 1688.62 & 2.09 \\
\hline \multicolumn{7}{|l|}{$(A \times B)$} \\
\hline Theoretical lactate uptake capacity & 15.75 & 34.34 & 2.20 & 5964.40 & 5232.80 & 0.86 \\
\hline
\end{tabular}

to support brain energy homeostasis in this group of ectotherms. Moreover, the results on mRNA transcript and spatial expressions in brain together with functional characterization in oocytes could demonstrate that the timely activations of drMCT2a mRNA as well as drMCT4b kinetic properties are probably more essential for nutrient supply in neurons compared to other isoforms under hypothermic stress.

\section{Conclusion}

To our best knowledge, the present work is the first report on the differential in vivo and in vitro responses of MCT isoforms expressed in fish brain during cold shock. The present study identified relevant MCT isoforms in zebrafish and analyzed their differential relevance for lactate transport in zebrafish brain in vivo and in vitro under hypothermic stress. In accordance with our previous study demonstrating different MCT isoforms' spatial localization and functional characterization in zebrafish [57], the present study further indicates a lactate utilization pathway between astrocytes and neurons summarized in Figure 11. Our findings corroborate earlier studies in rainbow trout showing conserved features of a ANLSH in the teleost brain which is similar to that described in mammalian systems [68]. Future studies will investigate the lactate transport kinetics of all seven drMCT isoforms in combination with specific inhibitors in order broaden our understanding regarding isoform-specific lactate transport characteristics. Although lactate is deemed as a toxic metabolite for cells this work highlights its important role in fast energy supply during cold stress to maintain brain functionality in fish. Therefore lactate utilization is not only beneficial for fish brain to maintain physiological status by mediating glucosensing system, but also plays a substantial nourishment role under hypothermic stress. In this context the transport of lactate via MCT paralogues has been demonstrated to represent a novel, highly dynamic process that can be differentially expressed even under non-stressful conditions, and can additionally be timely regulated in response to ambient temperature as well. These unique characteristics of MCTs may represent an important feature in ectothermic animals that enables utilization of lactate and thus, supports energy homeostasis in fish brain under acute cold stress.

\section{Materials and methods}

Experimental animals Zebrafish

The wild type $\mathrm{AB}$ strain of adult zebrafish (Danio rerio) were obtained from the stock of the Institute of Cellular and Organismic Biology, Academia Sinica. Animals were kept in a circulating system at $28^{\circ} \mathrm{C}$ under 14 hour/ 10 hour of light/dark photoperiod. Fish were fed with dry food (Hai Feng, Nantou, Taiwan) twice a day.

\section{Xenopus laevis}

Imported mature female African $X$. laevis frogs were purchased from the African Xenopus facility c.c., Noordhoek, South Africa. They were housed in cages in $18^{\circ} \mathrm{C}$ carbonfiltered water under standard conditions, and were fed small-sized live goldfish. Through an abdominal small $(<1 \mathrm{~cm})$ incision, oocytes were isolated by a partial ovariectomy from female Xenopus anesthetized with $0.1 \%$ tricaine (3-aminobenzoic acid ethyl ester) on ice. The incision was sutured, and the animal was monitored during the recovery period before it was returned to its tank. Oocytes were maintained at $18^{\circ} \mathrm{C}$ in Barth's solution containing $88 \mathrm{mM} \mathrm{NaCl}, 1 \mathrm{mM} \mathrm{KCl}, 2.4 \mathrm{mM} \mathrm{NaHCO} 3,0.3 \mathrm{mM}$ $\mathrm{CaN}_{2} \mathrm{O}_{6}, 0.41 \mathrm{mM} \mathrm{CaCl}, 0.82 \mathrm{mM} \mathrm{MgSO}_{4}$, and $15 \mathrm{mM}$ HEPES (pH 7.6), with gentamycin $(20 \mu \mathrm{g} / \mathrm{mL})$. Oocytes were utilized within 2 days after sampling.

\section{Hypothermic experiments}

Zebrafish acclimated in $28^{\circ} \mathrm{C}$ for over than six months and were directly transferred to $18^{\circ} \mathrm{C}$ circulating tanks. 8 males and 8 females (body length: $4.0 \sim 4.5 \mathrm{~cm}$ ) were collected and both incubated in $5 \mathrm{~L}$ aquaria which were placed in a $300 \mathrm{~L}$ water bath at a constant temperature of $18 \pm 0.5^{\circ} \mathrm{C}$. The four replicate tanks were randomly distributed within the water bath and connected to a flow through system providing freshwater. After $1 \mathrm{~h}$ and $24 \mathrm{~h}$ cold transferred, fish were anesthetized with 


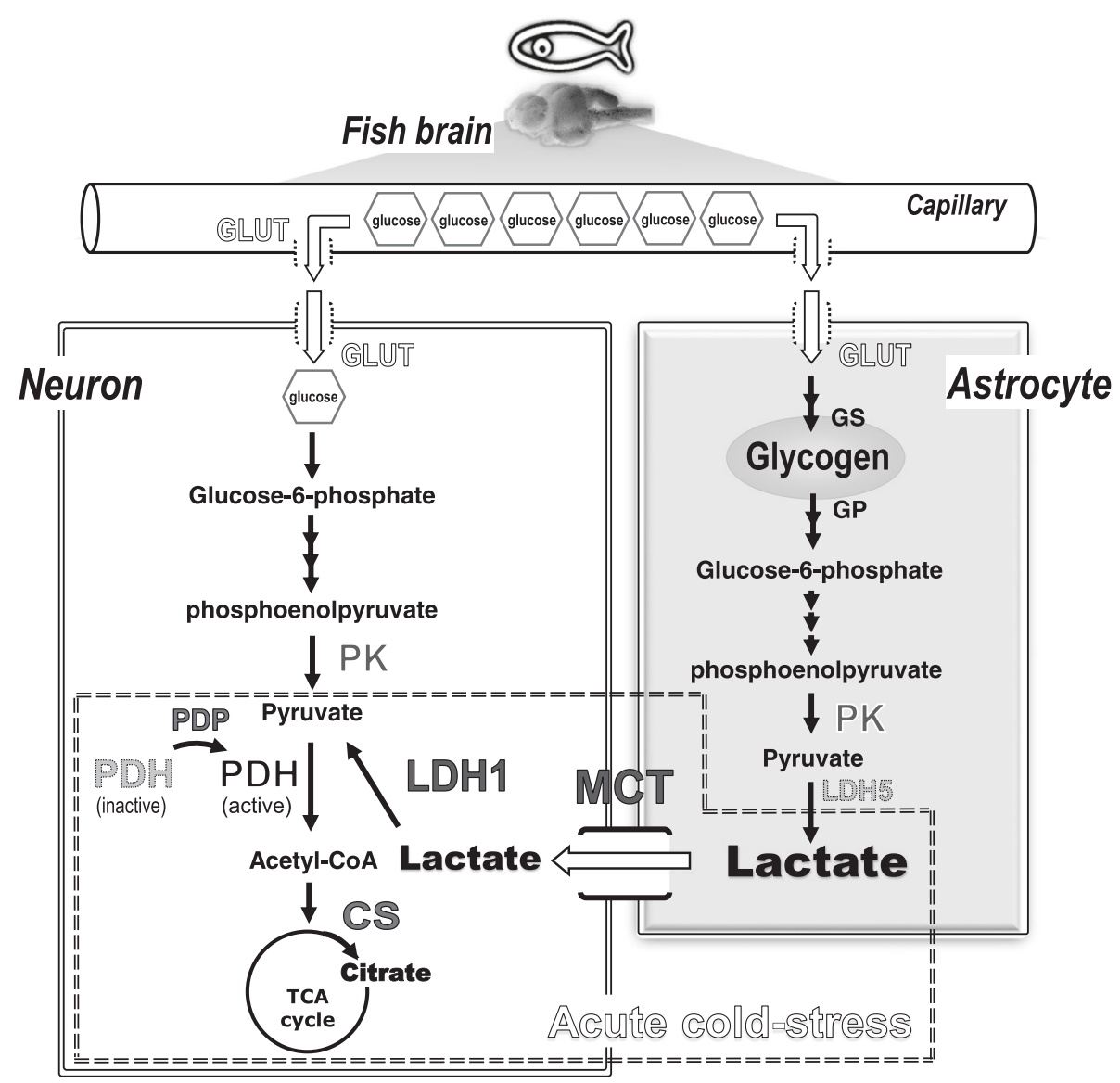

Figure 11 Proposed model for glucose and lactate metabolism in ectothermic fish brain neurons and astrocytes. Lactate is metabolized from glycogenolysis via LDH5 and accumulated in astrocytes. In case of environmental cold stress, lactate is rapidly transport to adjacent neurons through MCT and then converted to pyruvate for immediate ATP production and supply. Different expression patterns of MCT homologues can mediate compensatory function for monocarboxylate transport between neurons and astrocytes in fish brain. Confirmed transporter and enzymes (MCT, LDH1, PK, CS and PDP) are colored as black or dark grey whereas the LDH5 proteins is not yet confirmed and thus hypothetical (light grey).

buffered MS222 (Sigma, St. Louis, MO, USA) before sampling and brains were sampled for total RNA, protein extraction and glucose/lactate content analysis. They were always sacrificed at the same time between 11:00 AM to 12:00 AM, in order to minimize the effect of circadian rhythm. In addition, our preliminary test could demonstrate that oxygen consumption rates were not affected by food deprivation for $24 \mathrm{~h}$ at $28^{\circ} \mathrm{C}$. Therefore during the acclimation experiments, fish were not fed.

\section{Oxygen consumption and $\mathrm{NH}_{4}^{+}$excretion rates}

Oxygen consumption rates were determined by closed respirometry in $2 \mathrm{~L}$ respiration chambers at atmospheric pressure. Three chambers were filled with filtered freshwater $(0.2 \mu \mathrm{m})$ and equipped with three animals each. An additional chamber without fish served as a control. Fish were pre acclimated in the respiration chamber for 2-h while the water was aerated to reach full oxygen saturation. After closing the respiration chambers animals were incubated for $1 \mathrm{~h}$. In order to keep the incubation temperature constant, test chambers were placed in a temperature controlled water bath. A decrease of oxygen concentrations below $70 \%$ was avoided. Before and after incubation, water samples $(3 \times 50 \mathrm{ml}$ plus overflow $)$ were carefully siphoned off from each respiration chamber, and the amount of dissolved oxygen was determined following the Winkler method [79]. The amount of oxygen consumed by bacteria (control chamber) was subtracted from the overall oxygen consumption of the fish. Oxygen consumption rates were expressed as $\mu$ mole $/ \mathrm{mg}_{F W^{*}}$ h.

To assess the effect of hypothermic treatment on ammonia excretion, one fish was placed in a $3 \mathrm{~L}$ tank, and $400 \mu \mathrm{L}$ of water samples were be collected from the incubation water at the start of the experiment and after 1 - and 24-h incubation respectively. Water samples were deproteinized in 4 volumes of ice-cold $6 \%$ perchloric acid, and centrifuged at $16000 \mathrm{~g}$ for $15 \mathrm{~min}$ at $4^{\circ} \mathrm{C}$. The supernatant was further neutralized with ice-cold $2 \mathrm{M}$ 
$\mathrm{K}_{2} \mathrm{CO}_{3}$ and spun again at $16000 \mathrm{~g}$ for $10 \mathrm{~min}\left(4^{\circ} \mathrm{C}\right)$. The final supernatant was directly analyzed for $\mathrm{NH}_{4}^{+}$concentrations using a tissue ammonia kit (AA0100; Sigma, St Louis, MO, USA). Ammonia contents in the incubation water were determined colorimetrically at an absorbance of $390 \mathrm{~nm}$ with a Synergy HT spectrophotometer (BIOTEK, Winooski, Vermont, VT, USA).

\section{Glucose and L-lactate content analysis}

Isolated brain tissues were homogenized by polytron disruption with 7.5 volume of ice-cooled $6 \%$ perchloric acid (PCA), and neutralized (using $1 \mathrm{M}$ potassium bicarbonate). The homogenate was centrifuged at $1000 \times \mathrm{g}$ for $15 \mathrm{~min}$ in $4^{\circ} \mathrm{C}$, and the supernatant was used for the following assay. Glucose and lactate levels in zebrafish brain were assessed using the glucose and lactate assay kit (BioVision, Mountain View, CA, USA) following the manufacturer's protocols. Both, glucose and lactate contents were measured at $570 \mathrm{~nm}$ with a Synergy HT spectrophotometer (BIO-TEK) for colorimetric assay. Each sample was assayed in triplicate.

\section{Western blotting}

Isolated brain tissues were disrupted in homogenization buffer (100 mM imidazole, 5 mM EDTA, $200 \mathrm{mM}$ sucrose, and $0.1 \%$ sodium deoxycholate; $\mathrm{pH} 7.6$ ), and then centrifuged at $4^{\circ} \mathrm{C}$ and $10,000 \mathrm{rpm}$ for $10 \mathrm{~min}$. The supernatant (a volume equivalent to $20 \mu \mathrm{g}$ protein) was supplemented with electrophoresis sample buffer (250 mM Tris-base, $2 \mathrm{mM} \mathrm{Na}{ }_{2}$ EDTA, 2\% SDS, and 5\% dithiothreitol), and then incubated at $95^{\circ} \mathrm{C}$ for $10 \mathrm{~min}$. The denatured samples were subjected to $10 \%$ sodium dodecylsulfate (SDS)-polyacrylamide gel electrophoresis then transferred to polyvinylidene difluoride membranes (Millipore, Billerica, CA, USA). After blocking in $5 \%$ nonfat milk, the blots were incubated with a mouse anti-human lactate dehydrogenase 1 (LDH1) monoclonal antibody (Acris Antidodies GmbH, Germany, diluted 1:1000), a mouse anti-porcine citrate synthase (CS) monoclonal antibody (US Biological, Massachusetts, MA, USA, diluted 1:1000) and a mouse anti-chicken $\alpha$-tubulin (Sigma), respectively. Blots were then incubated with alkaline phosphatase (AP)-conjugated goat anti-mouse immunoglobulin G (Pierce, Rockford, IL, USA, diluted 1:1000) for one hour. The immunoreactive proteins were visualized with a 5-bromo-4-chloro3-indolyl phosphate (BCIP)/nitro blue tetrazolium (NBP) substrate kit for AP (Zymed Laboratories, San Francisco, CA, USA). Immunoblots were scanned and exported to TIFF files, and the differences between the band intensities of control fishes and cold acclimation fishes were compared using a commercial software package (Image-Pro Plus 7.0, Media Cybernetics, Silver Spring, MD, USA).

\section{Preparation of total RNA}

250-300 mg brain tissue were collected and homogenized in $4 \mathrm{~mL}$ of Trizol Reagent (Invitrogen, Carlsbad, CA, USA). Genomic DNA was removed by treating total RNA with DNase I (Promega, Madison, WI, USA) at $37^{\circ} \mathrm{C}$ for $15 \mathrm{~min}$, and then total RNA was purified by a RNA purification kit (MasterPureTM, EPICENTRE Biotechnologies, Madison, WI, USA). The amount and quality of total RNA were determined by measuring the absorbance at $260 \mathrm{~nm}$ and $280 \mathrm{~nm}$ with NanoDrop spectrophotometer (ND-1000, NadroDrop Technologies, Wilmington, Delaware, USA). Then the completeness of total RNA was checked by RNA denatured gels. The total RNA pellets were stored at $-20^{\circ} \mathrm{C}$.

\section{Cloning, phylogenetic analysis and transmembrane prediction}

In-silico predicted full-length of zebrafish (D. rerio) MCT (drmct) homologues obtained from the genome were carefully confirmed by the NCBI database. Specific primers (as listed in Additional file 1: Table S1) were designed for the reverse-transcriptase polymerase chain reaction (RT-PCR) analysis. PCR products were subcloned into a pGEM-T Easy vector (Promega, Madison, WI, USA), and the nucleotide sequences were determined with an ABI 377 sequencer (Applied Biosystems, Warrington, UK). Sequence analysis was conducted with a BLASTx program (NCBI).

To verify the membership of identified candidates in the core MCT protein family, the deduced amino-acid sequences of cloned zebrafish MCTs were aligned with ClustalX together with all known MCT protein sequences available from public databases (referred to Table 2) and subjected to phylogenetic inferences using the Neighbor-joining (NJ) method. 10,000 bootstrap replicate analyses were carried out with MEGA 5.

Protein transmembrane predictions were generated using the "HMMTOP" program (http://www.enzim.hu/ hmmtop/). On the basis of physicochemical properties (i.e. hydrophobicity, charges, and distribution) of drMCT paralogues' amino acid residues and membrane-spanning features, the two-dimensional model images were created by a TMRPres2D software (http://biophysics.biol.uoa.gr/ TMRPres2D/).

\section{Reverse transcription-PCR analysis}

Total RNA extracted from brain, eye, gill, heart, stomach, intestine, spleen, liver, kidney, testis, ovary and muscle of zebrafish were diluted to equal concentration as template for reverse transcription ( $5 \mu \mathrm{g}$ total RNA/reaction). The final volume of $20 \mu \mathrm{L}$ contained $0.5 \mathrm{mM}$ dNTPs, $2.5 \mu \mathrm{M}$ oligo $_{(\mathrm{dT})} 20$ primer, $5 \mathrm{mM}$ dithiothreitol, and 200 units PowerScript reverse transcriptase III (Invitrogen, Carlsbad, CA, USA) and was incubated for 
Table 2 Summary of the known and predicted homologs of solute carrier 16A (SLC16A) protein family SLC16A1 orthologues

\begin{tabular}{|c|c|c|c|c|}
\hline Gene name & Protein & Species & Gene loci & Accession/Prediction Numbers \\
\hline hsSLC16A1 & hsMCT1 & Homo sapiens & Ch.1: $113.4 \mathrm{~m}$ & NP_003042 \\
\hline mmSLC16A1 & mmMCT1 & Mus musculus & Ch.3: $104.6 \mathrm{~m}$ & NP_033222 \\
\hline ggSLC16A1 & ggMCT1 & Gallus gallus & Ch.26: $3.55 \mathrm{~m}$ & NP_001006323 \\
\hline xtSLC16A1 & xtMCT1 & Xenopus_tropicalis & Scaffold GL172654.1:2.6m & NP_001015931 \\
\hline drSLC16A1a & drMCT1a & Danio rerio & Ch.8: $27.7 \mathrm{~m}$ & NP_956379 \\
\hline drSLC16A1b & drMCT1b & Danio rerio & Ch.6: $48.9 m$ & XP_005172152 \\
\hline tnSLC16A1a & tnMCT1a & Tetraodon_nigroviridis & Ch.Un_random:50.4m & ENSTNIP00000004779 \\
\hline $\operatorname{tnSLC16A1b}$ & tnMCT1b & Tetraodon_nigroviridis & Ch. $11: 8.5 \mathrm{~m}$ & ENSTNIP00000021447 \\
\hline olSLC16A1a & olMCT1a & Oryzias latipes & Ch.7: $26.4 \mathrm{~m}$ & ENSORLP00000020855 \\
\hline olSLC16A1b & olMCT1a & Oryzias latipes & Ch.5: $11.9 \mathrm{~m}$ & ENSORLP00000008214 \\
\hline onSLC16A1a & onMCT1a & Oreochromis_niloticus & Scaffold GL831365.1: 0.77m & ENSONIP00000020865 \\
\hline onSLC16A1b & onMCT1b & Oreochromis_niloticus & Scaffold GL831272.1: 0.54m & ENSONIP00000018476 \\
\hline \multicolumn{5}{|c|}{ SLC16A7 orthologues } \\
\hline Gene name & Protein & Species & Gene loci & Accession/Prediction Numbers \\
\hline hsSLC16A7 & hsMCT2 & Homo sapiens & Ch.12: $59.9 \mathrm{~m}$ & NP_004722 \\
\hline mmSLC16A7 & $\mathrm{mmMCT2}$ & Mus musculus & Ch.10: $125.2 \mathrm{~m}$ & NP_035521 \\
\hline ggSLC16A7 & ggMCT2 & Gallus gallus & Ch.1: $31.9 \mathrm{~m}$ & XP_416057 \\
\hline xtSLC16A7a & xtMCT2a & Xenopus_tropicalis & Scaffold GL173247.1:0.46m & NP_001106392 \\
\hline$x t S L C 16 A 7 b$ & xtMCT2b & Xenopus_tropicalis & Scaffold GL173000.1: 0.36m & ENSXETP00000005367 \\
\hline drSLC16A7a & drMCT2a & Danio rerio & Ch.23: $9.9 \mathrm{~m}$ & NP_001092889 \\
\hline $\mathrm{drSLC16A7b}$ & drMCT2b & Danio rerio & Scaffold Zv9_NA123: 35,158 & ENSDARP00000097781 \\
\hline olSLC16A7a & olMCT2a & Oryzias latipes & Ch.23: $1.1 \mathrm{~m}$ & ENSORLP00000011457 \\
\hline olSLC16A7b & olMCT2b & Oryzias latipes & Ch.7: $20.8 \mathrm{~m}$ & ENSORLP00000017081 \\
\hline oISLC16A7C & olMCT2C & Oryzias latipes & Ch.5: $15.1 \mathrm{~m}$ & ENSORLP00000010065 \\
\hline
\end{tabular}

\section{SLC16A7 orthologues}

\begin{tabular}{|c|c|c|c|c|}
\hline Gene name & Protein & Species & Gene loci & Accession/Prediction Numbers \\
\hline $\operatorname{tnSLC16A7a}$ & tnMCT2a & Tetraodon_nigroviridis & Ch.19: $6.4 \mathrm{~m}$ & ENSTNIP00000009708 \\
\hline $\operatorname{tnSLC16A7b}$ & $\operatorname{tnMCT2b}$ & Tetraodon_nigroviridis & Ch.9:8.2m & ENSTNIP00000015526 \\
\hline $\operatorname{tnSLC16A7C~}$ & $\operatorname{tnMCT2C}$ & Tetraodon_nigroviridis & Ch.11: 2.3m & ENSTNIP00000014066 \\
\hline onSLC16A7a & onMCT2a & Oreochromis_niloticus & Scaffold GL831168.1:2.6m & ENSONIP00000012517 \\
\hline onSLC16A7b & onMCT2b & Oreochromis_niloticus & Scaffold GL831137.1: 4.3m & ENSONIP00000021355 \\
\hline onSLC16A7C & onMCT2C & Oreochromis_niloticus & Scaffold GL831152.1: 4.9m & ENSONIP00000025647 \\
\hline \multicolumn{5}{|c|}{ SLC16A8 orthologues } \\
\hline Gene name & Protein & Species & Gene loci & Accession/Prediction Numbers \\
\hline hsSLC16A8 & hsMCT3 & Homo sapiens & Ch.22: $38.4 \mathrm{~m}$ & NP_037488 \\
\hline $\mathrm{mmSLC} 16 \mathrm{~A} 8$ & mmMCT3 & Mus musculus & Ch.15: $79.2 \mathrm{~m}$ & NP_065262 \\
\hline ggSLC16A8 & ggMCT3 & Gallus gallus & Ch.1: 50.8m & NP_990471 \\
\hline ICSLC16A8 & ICMCT3 & Latimeria_chalumnae & ScaffoldJH127309.1: 0.25m & ENSLACP00000007957 \\
\hline drSLC16A8 & drMCT3 & Danio rerio & Ch.12: $20.2 \mathrm{~m}$ & XP_686130 \\
\hline \multicolumn{5}{|c|}{ SLC16A3 orthologues } \\
\hline Gene name & Protein & Species & Gene loci & Accession/Prediction Numbers \\
\hline hsSLC16A3 & hsMCT4 & Homo sapiens & Ch.17: $80.1 \mathrm{~m}$ & NP_001035887 \\
\hline $\mathrm{mmSLC16A3}$ & mmMCT4 & Musmusculus & Ch.11: 120.9m & NP_001033743 \\
\hline ggSLC16A3 & ggMCT4 & Gallus gallus & Ch.18: 4.8m & NP_989994 \\
\hline
\end{tabular}


Table 2 Summary of the known and predicted homologs of solute carrier 16A (SLC16A) protein family (Continued)

\begin{tabular}{lllll}
\hline xtSLC16A3 & xtMCT4 & Xenopus_tropicalis & Scaffold GL172918.1: 1.0m & NP_001007912 \\
drSLC16A3a & drMCT4a & Danio rerio & Ch.12: $\mathbf{3 4 . 8 m}$ & NP_997873 \\
drSLC16A3b & drMCT4b & Danio rerio & Ch.3: $\mathbf{3 6 . 1 m}$ & ENSDARP00000032530 \\
olSLC16A3 & olMCT4 & Oryzias latipes & Ch.8: $25.2 \mathrm{~m}$ & ENSORLP00000021568 \\
tnSLC16A3a & tnMCT4a & Tetraodon_nigroviridis & Ch.Un_random:5.2m & ENSTNIP00000017000 \\
tnSLC16A3b & tnMCT4b & Tetraodon_nigroviridis & Ch.Un_random:38.6m & ENSTNIP00000006385 \\
onSLC16A3a & onMCT4a & Oreochromis_niloticus & Scaffold GL831179.1: 0.76m & ENSONIP00000007853 \\
onSLC16A3b & onMCT4b & Oreochromis_niloticus & Scaffold GL831279.1: $1.7 \mathrm{~m}$ & ENSONIP00000009194
\end{tabular}

Gene loci organization in the genomic region are collected from the Release 75 (February2014) of ENSEMBL Genome Browser.

$90 \mathrm{~min}$ at $50^{\circ} \mathrm{C}$ followed by $15 \mathrm{~min}$ incubation at $70^{\circ} \mathrm{C}$. Then 20 units Escherichia coli RNase H (Invitrogen, Carlsbad, CA, USA) was added to remove the remnant RNA. For PCR amplification, $2 \mu \mathrm{L}$ total cDNA was used as template in a $50 \mu \mathrm{L}$ final reaction volume containing $0.25 \mathrm{mM}$ dNTPs, 2 units ExTaq polymerase (Takara, Shiga, Japan), and $0.2 \mu \mathrm{M}$ of each primer. Primers were designed against specific regions of each isoform according to the drMCT alignment results (Figure 6). The primer sets for the PCR are shown in Additional file 1: Table S1. Zebrafish ribosomal protein L13A (zrpl13a) was used to evaluate the relative amounts of cDNAs as an internal control. This gene has been demonstrated to serve as a suitable reference gene in zebrafish under diverse experimental treatments and different developmental periods [80]. All amplicons were sequenced to ensure that PCR products corresponded to the desired gene fragments.

\section{Quantitative real-time PCR (qRT-PCR) analysis of gene expressions}

Total RNA was extracted and reverse-transcribed from zebrafish brain as described above. Real-time PCR was performed with Roche LightCycler ${ }^{\circledR} 480$ System (Roche Applied Science, Mannheim, Germany). The primers for all genes were designed (Additional file 1: Table S1) using Primer Premier 5.0 software (PREMIER Biosoft Int., Palo Alto, CA, USA). The final volume of $10 \mu \mathrm{L}$ containing $40 \mathrm{ng}$ of cDNA, $50 \mathrm{nM}$ of each primer and the LightCycler ${ }^{\circ} 480$ SYBR Green I Master (Roche). The standard curve of each gene was checked in linear range with drrpl13a as an internal control. All qRT-PCR reactions were administered as follows: 1 cycle of $50^{\circ} \mathrm{C}$ for $2 \mathrm{~min}$ and $95^{\circ} \mathrm{C}$ for $10 \mathrm{~min}$, followed by 45 cycles of $95^{\circ} \mathrm{C}$ for $15 \mathrm{sec}$ and $60^{\circ} \mathrm{C}$ for $1 \mathrm{~min}$. PCR products were subjected to melting-curve analysis, and representative samples were electrophoresed to verify that only a single product was present. All primer pairs used in this PCR had efficiencies $>94 \%$. Control reactions were conducted with sterile water to determine the levels of the background and genomic DNA contamination.
Fluorescent in situ hybridization and immunocytochemical staining

Digoxigenin (DIG)-labeled RNA probes of drmct1b, $d r m c t 2 b$ and drmct $4 b$ sense and antisense strands were synthesized by in vitro transcription using DIG-labeling mix (Roche, Grenzach-Wyhlen, Germany) according to the manufacturer's instructions. RNA probes were examined on RNA gels.

The brain was dissected out of the adult zebrafish head capsule and then sliced into transverse sections of $50 \mu \mathrm{m}$ using a vibrating blade microtome (VT-1200S, Leica, Wetzlar, Germany). Sliced brain samples were attached to poly- ${ }_{\mathrm{L}}$-lysine-coated slides (Erie, Portsmouth, $\mathrm{NH}$, USA). Prepared slides were washed with PBST and then hybridized with prepared probes at $65^{\circ} \mathrm{C}$ for overnight incubation. On the next day, slides were washed in a hybridization buffer series in $2 \times \mathrm{SSC}$ at $65^{\circ} \mathrm{C}$. After another serial washing with $0.2 \times \mathrm{SSC}$ and PBST, samples were incubated with $5 \%$ sheep serum in $2 \mathrm{mg} / \mathrm{mL}$ bovine serum albumin (BSA), and then the anti-DIG-POD antibody (Roche) was added at a 1:500 dilution. Slides were then washed with PBST and stained with the Alexa 488tyramide substrate (1:100 dilution). After being washed with PBST and 100\% methanol, slides were incubated in an $\mathrm{H}_{2} \mathrm{O}_{2}$ /methanol solution to inactivate the POD. The validity of antisense RNA probes' signals was further examined by the same experiments utilizing sense probes (data not shown). After in situ hybridization, zebrafish brain slides were rinsed in PBS, and blocked with 3\% BSA. Afterwards, slides first incubated with the ZN12 monoclonal antibody (Institute of Neuroscience, University of Oregon, Eugene, OR, USA; diluted $1: 100)$ to label neurons, or with the glial fibrillary acidic protein (GFAP) mAb (DAKO, Glostrup, Denmark; diluted $1: 100)$ to label astrocytes. After washing with PBS, slides were incubated in anti-mouse IgG conjugated with Alexa Fluor 568 (1:300; Molecular Probes, Eugene, OR, USA). Then slides were washed with PBS. Images were acquired with a Leica TCS-SP5 confocal laser scanning microscope (Leica Lasertechnik, Heidelberg, Germany). 


\section{Synthesis of drmct homologue capped mRNA (cRNA)}

The open-reading frame of drmct homologues and the designed anchor sites (XhoI and BamHI) were PCRamplified using primers based on gene coding sequence, including its stop codon. They were cloned into a pGEM$\mathrm{T}$ easy vector (Promega, Madison, WI, USA) and sequenced. The PCR products were then digested with XhoI and BamHI and subcloned in-frame into the $\mathrm{pCS} 22_{\mathrm{XLT}}$ vector, in which the signal sequence was not fused with the $\mathrm{N}$-terminus of the green fluorescent protein GFP. Capped mRNA (cRNA) encoding drmct paralogues were transcribed using the SP6 mMessage mMachine (Ambion, Austin, TX, USA) from plasmid template linearized with NotI (Promega, Madison, WI, USA).

\section{Expression of drmct homologues in X. laevis oocytes}

$5 \mathrm{ng}$ of drmct homologue cRNA was microinjected into stage V-VI Xenopus oocytes. An equal volume of RNasefree modified Barth's saline (MBS, containing $85 \mathrm{mM}$ $\mathrm{NaCl}, 1 \mathrm{mM} \mathrm{KCl}, 2.4 \mathrm{mM} \mathrm{NaHCO} 3,0.82 \mathrm{mM} \mathrm{MgSO}_{4}$, $0.33 \mathrm{mM} \mathrm{Ca}\left(\mathrm{NO}_{3}\right)_{2}, 0.41 \mathrm{mM} \mathrm{CaCl} 2,10 \mathrm{mM}$ HEPES, $3 \mathrm{mM} \mathrm{NaOH}, \mathrm{pH}$ 7.4, supplemented with 10 units/ml penicillin and $10 \mu \mathrm{g} / \mathrm{ml}$ streptomycin) was also injected to serve as the control group. After culturing for 2 days at $18^{\circ} \mathrm{C} \mathrm{MBS}$, the uptake experiment was initiated by transferring and incubating the oocytes at $18^{\circ} \mathrm{C}$ or $28^{\circ} \mathrm{C}$ in $500 \mu \mathrm{L}$ MBS medium for $6 \mathrm{~h}$ and then $5 \mathrm{kBq} / \mathrm{ml}$ of $\mathrm{L}^{-}$ $\left[{ }^{14} \mathrm{C}\right]$-lactate (Amersham, Piscataway, NJ, USA) was added into the MBS medium. After incubation in L-[14C]-lactate containing MBS medium for $2 \mathrm{~h}$, the uptake reaction was terminated by adding $2 \mathrm{~mL}$ of ice-cold MBS, followed by washing the oocytes five times with $2 \mathrm{~mL}$ MBS. After the wash, each oocyte was dissolved with $300 \mu \mathrm{L}$ of $10 \%$ SDS. Radioactivity was determined by adding $2 \mathrm{~mL}$ of ACSII (Amersham) to each solubilized oocyte in a liquid scintillation counter and then total L-[14C]-lactate concentration in experimental oocytes was determined in a beta counter (LS6500 Liquid Scintillation Counter, Beckman Coulter, Fullerton, CA, USA). The lactate uptake rate of MBS injected oocytes is subtracted from the uptake rate of MCT expressing oocytes and presented as nmole/hr per oocyte.

\section{Statistical analysis}

Values are presented as mean \pm standard deviation (SD). The level of significance was set to $p<0.05$ in a oneway ANOVA (Tukey's pairwise comparison) for calculating intact $\mathrm{O}_{2}$ consumption and ammonium excretions of zebrafish; glucose and ${ }_{\mathrm{L}}$-lactate contents in brain; LDH1 protein relative abundance; homologues of $d r p k$, $d r p d p$ and drmct mRNA expression levels; $\mathrm{L}_{-}\left[{ }^{14} \mathrm{C}\right]$-lactate transport characterizations of drMCT2a and drMCT4b for each time point along cold treatment. Student's t-test was used for analyzing ammonium concentration, CS protein expression and $\mathrm{L}^{-}\left[{ }^{14} \mathrm{C}\right]$-lactate uptake between control $\left(28^{\circ} \mathrm{C}\right)$ and hypothermic $\left(18^{\circ} \mathrm{C}\right)$ groups. Different letters indicate significant differences between treatments $(p<$ $0.05)$, whereas same letters indicate no significant differences between treatments $(p>0.05)$. Asterisks indicate significant different between control and hypothermic group (Student's t-test, $p<0.05$ ).

\section{Additional file}

Additional file 1: Table S1. Primer used for RT-PCR and real-time PCR.

\section{Competing interests}

The authors declare that they have no competing interests.

\section{Authors' contributions}

YCT, STL and MYH designed and conducted experiment, analyzed the data and compiled the manuscript. STL, MYH and JRL conducted oxygen consumption and ammonium excretion experiments and analyzed the data. RDC carried out the molecular cloning studies and gene expression analysis. All authors read and approved the final manuscript.

\section{Acknowledgements}

This study was financially supported by the grants to Y. C. Tseng from the National Science Council, Taiwan, Republic of China (NSC 102-2321-B-003 -002) and an Alexander von Humbold/National Science Council (Taiwan) grant awarded to M. H. (NSC 102-2911-I-001-002-2).

\section{Author details}

'Department of Life Science, National Taiwan Normal University, Taipei City, Taiwan. ${ }^{2}$ Institute of Cellular and Organismic Biology, Academia Sinica, Nankang, Taipei City, Taiwan.

\section{Received: 18 February 2014 Accepted: 11 July 2014}

Published: 8 August 2014

\section{Reference}

1. Tseng YC, Chen RD, Lucassen M, Schmidt MM, Dringen R, Abele D, Hwang PP: Exploring uncoupling proteins and antioxidant mechanisms under acute cold exposure in brains of fish. PLoS One 2011, 6:e18180.

2. Windisch HS, Kathöver R, Pörtner H-O, Frickenhaus S, Lucassen M: Thermal acclimation in Antarctic fish: Transcriptomic profiling of metabolic pathways. Am J Physiol Regul Integr Comp Physiol 2011, 301:R1453-R1466.

3. Shabtay A, Arad Z: Ectothermy and endothermy: evolutionary perspectives of thermoprotection by HSPs. J Exp Biol 2005, 208:2773-2781

4. Pörtner HO, Hardewig I, Sartoris FJ, Van Dijk PLM: Energetic Aspects of Cold Adaptation: Critical Temperatures in Metabolic, lonic and Acid-Base Regulation. Cambridge: Cambridge University Press; 1998.

5. Eckerle L, Lucassen M, Hirse T, Pörtner H-O: Cold induced changes of adenosine levels in common eelpout (Zoarces viviparus): a role in modulating cytochrome c oxidase expression. J Exp Biol 2008, 211:1262-1269.

6. Kawall H, Torres J, Sidell B, Somero G: Metabolic cold adaptation in Antarctic fishes: evidence from enzymatic activities of brain. Mar Biol 2002, 140:279-286.

7. Somero GN, Fields PA, Hofmann GE, Weinstein RB, Kawall H: Cold adaptation and stenothermy in Antarctic notothenioid fishes: what has been gained and what has been lost? In Fishes of Antarctica. Milan: Springer; 1998:97-109.

8. Soengas $\lrcorner L$, Aldegunde M: Energy metabolism of fish brain. Comp Biochem Physiol B Biochem Mol Biol 2002, 131:271-296.

9. Magistretti PJ, Allaman I: Brain energy Metabolism. In Neuroscience in the 21st Century. New York: Springer; 2013:1591-1620.

10. Magistretti PJ, Pellerin L: Astrocytes couple synaptic activity to glucose utilization in the brain. News Physiol Sci 1999, 14:177-182.

11. Buzsáki G, Kaila K, Raichle M: Inhibition and brain work. Neuron 2007 , 56:771-783 
12. Hylland P, Milton S, Pek M, Nilsson GE, Lutz PL: Brain $\mathrm{Na}^{+} / \mathrm{K}^{+}$-ATPase activity in two anoxia tolerant vertebrates: crucian carp and freshwater turtle. Neurosci Lett 1997, 235:89-92

13. Purdon A, Rapoport S: Energy requirements for two aspects of phospholipid metabolism in mammalian brain. Biochem J 1998, 335:313-318.

14. Alvarez Jl, Katayama T, Prat A: Glial influence on the blood brain barrier. Glia 2013, 61:1939-1958.

15. Simpson IA, Carruthers A, Vannucci SJ: Supply and demand in cerebral energy metabolism: the role of nutrient transporters. J Cereb Blood Flow Metab 2007, 27:1766-1791.

16. Tanaka K: Role of glutamate transporters in brain development. Nippon Yakurigaku Zasshi 2007, 130:455.

17. Bélanger M, Allaman I, Magistretti PJ: Brain energy metabolism: focus on astrocyte-neuron metabolic cooperation. Cell Metab 2011, 14:724-738.

18. Mergenthaler $P$, Lindauer $U$, Dienel GA, Meisel A: Sugar for the brain: the role of glucose in physiological and pathological brain function. Trends Neurosci 2013, 36:587-597.

19. Hertz L, Peng L: Energy metabolism at the cellular level of the CNS. Can J Physiol Pharmacol 1992, 70:S145-S157.

20. Bolaños JP, Almeida A, Moncada S: Glycolysis: a bioenergetic or a survival pathway? Trends Biochem Sci 2010, 35:145-149.

21. Rodriguez-Rodriguez $P$, Almeida A, Bolaños JP: Brain energy metabolism in glutamate-receptor activation and excitotoxicity: Role for APC/C-Cdh1 in the balance glycolysis/pentose phosphate pathway. Neurochem Int 2013, 62:750-756

22. Pellerin L, Halestrap AP, Pierre K: Cellular and subcellular distribution of monocarboxylate transporters in cultured brain cells and in the adult brain. J Neurosci Res 2005, 79:55-64.

23. Aubert A, Costalat R, Magistretti PJ, Pellerin L: Brain lactate kinetics: modeling evidence for neuronal lactate uptake upon activation. Proc Natl Acad Sci U S A 2005, 102:16448-16453.

24. Bittar PG, Charnay Y, Pellerin L, Bouras C, Magistretti PJ: Selective distribution of lactate dehydrogenase isoenzymes in neurons and astrocytes of human brain. J Cereb Blood Flow Metab 1996, 16:1079-1089.

25. Debernardi R, Pierre K, Lengacher S, Magistretti PJ, Pellerin L: Cell-specific expression pattern of monocarboxylate transporters in astrocytes and neurons observed in different mouse brain cortical cell cultures. J Neurosci Res 2003, 73:141-155.

26. Hanu R, McKenna M, O'Neill A, Resneck WG, Bloch RJ: Monocarboxylic acid transporters, $\mathrm{MCT} 1$ and $\mathrm{MCT} 2$, in cortical astrocytes in vitro and in vivo. Am J Physiol Cell Physiol 2000, 278:C921-C930.

27. Laughton J, Charnay Y, Belloir B, Pellerin L, Magistretti P, Bouras C: Differential messenger RNA distribution of lactate dehydrogenase LDH-1 and LDH-5 isoforms in the rat brain. Neuroscience 2000, 96:619-625.

28. Bouzier-Sore AK, Voisin P, Bouchaud V, Bezancon E, Franconi JM, Pellerin L: Competition between glucose and lactate as oxidative energy substrates in both neurons and astrocytes: a comparative NMR study. Eur J Neurosci 2006, 24:1687-1694

29. Morris ME, Felmlee MA: Overview of the proton-coupled MCT (SLC16A) family of transporters: characterization, function and role in the transport of the drug of abuse $\gamma$-hydroxybutyric acid. AAPS J 2008, 10:311-321

30. Halestrap AP, Meredith D: The SLC16 gene family-from monocarboxylate transporters (MCTs) to aromatic amino acid transporters and beyond. Pflugers Arch 2004, 447:619-628

31. Halestrap AP, Wilson MC: The monocarboxylate transporter family-role and regulation. IUBMB Life 2012, 64:109-119.

32. Merezhinskaya N, Fishbein WN: Monocarboxylate transporters: past, present, and future. Histol Histopathol 2009, 24:243.

33. Meredith $\mathrm{D}$, Christian $\mathrm{H}$ : The SLC16 monocaboxylate transporter family. Xenobiotica 2008, 38:1072-1106.

34. Pierre K, Pellerin L: Monocarboxylate transporters in the central nervous system: distribution, regulation and function. J Neurochem 2005, 94:1-14

35. Bergersen $L$, Thomas $M$, Johannsson E, Waerhaug O, Halestrap A, Andersen K, Sejersted O, Ottersen $O$ : Cross-reinnervation changes the expression patterns of the monocarboxylate transporters 1 and 4: an experimental study in slow and fast rat skeletal muscle. Neuroscience 2006, 138:1105-1113.

36. Chiry O, Pellerin L, Monnet-Tschudi F, Fishbein WN, Merezhinskaya N, Magistretti PJ, Clarke S: Expression of the monocarboxylate transporter MCT1 in the adult human brain cortex. Brain Res 2006, 1070:65-70.
37. Hashimoto T, Hussien R, Oommen S, Gohil K, Brooks GA: Lactate sensitive transcription factor network in L6 cells: activation of MCT1 and mitochondrial biogenesis. FASEB J 2007, 21:2602-2612

38. Bröer S, Rahman B, Pellegri G, Pellerin L, Martin J-L, Verleysdonk S, Hamprecht $B$, Magistretti PJ: Comparison of lactate transport in astroglial cells and monocarboxylate transporter 1 (MCT 1) expressing Xenopus laevis oocytes. Expression of two different monocarboxylate transporters in astroglial cells and neurons. J Bio/ Chem 1997, 272:30096-30102.

39. Broer S, Schneider H, Broer A, Rahman B, Hamprecht B, Deitmer J: Characterization of the monocarboxylate transporter 1 expressed in Xenopus laevis oocytes by changes in cytosolic pH. Biochem J 1998, 333:167-174.

40. Deuticke B: Monocarboxylate transport in erythrocytes. J Membr Bio/ 1982, 70:89-103

41. Deuticke B: Monocarboxylate transportr in red blood cell: kinetics and chemical modification. Methods Enzymol 1989, 173:300-329.

42. Poole RC, Halestrap AP: Transport of lactate and other monocarboxylates across mammalian plasma membranes. Am J Physiol Cell Physiol 1993, 264:C761-C782

43. Broer S, Broer A, Schneider H, STEGEN C, HALESTRAP A, DEITMER J: Characterization of the high-affinity monocarboxylate transporter MCT2 in Xenopus laevis oocytes. Biochem J 1999, 341:529-535.

44. Pierre K, Parent A, Jayet PY, Halestrap AP, Scherrer U, Pellerin L: Enhanced expression of three monocarboxylate transporter isoforms in the brain of obese mice. J Physiol 2007, 583:469-486.

45. Zhang SX, Searcy TR, Wu Y, Gozal D, Wang Y: Alternative promoter usage and alternative splicing contribute to mRNA heterogeneity of mouse monocarboxylate transporter 2. Physio/ Genomics 2007, 32:95-104.

46. Bergersen L: Is lactate food for neurons? Comparison of monocarboxylate transporter subtypes in brain and muscle. Neuroscience 2007, 145:11-19.

47. Philp NJ, Yoon H, Lombardi L: Mouse MCT3 gene is expressed preferentially in retinal pigment and choroid plexus epithelia. Am $J$ Physiol Cell Physiol 2001, 280:C1319-C1326

48. Yoon H, Fanelli A, Grollman EF, Philp NJ: Identification of a unique monocarboxylate transporter (MCT3) in retinal pigment epithelium. Biochem Biophys Res Commun 1997, 234:90-94.

49. Halestrap AP: The SLC16 gene family-Structure, role and regulation in health and disease. Mol Aspects Me 2013, 34:337-349.

50. Fox JEM, Meredith D, Halestrap AP: Characterisation of human monocarboxylate transporter 4 substantiates its role in lactic acid efflux from skeletal muscle. J Physio/ 2000, 529:285-293.

51. Polakof S, Míguez JM, Soengas JL: In vitro evidences for glucosensing capacity and mechanisms in hypothalamus, hindbrain, and Brockmann bodies of rainbow trout. Am J Physiol Regul Integr Comp Physiol 2007, 293:R1410-R1420.

52. Polakof S, Soengas JL: Involvement of lactate in glucose metabolism and glucosensing function in selected tissues of rainbow trout. J Exp Biol 2008, 211:1075-1086

53. Marty N, Dallaporta M, Thorens B: Brain glucose sensing, counterregulation, and energy homeostasis. Physiol 2007, 22:241-251.

54. Chou MY, Hsiao CD, Chen SC, Chen IW, Liu ST, Hwang PP: Effects of hypothermia on gene expression in zebrafish gills: upregulation in differentiation and function of ionocytes as compensatory responses. J Exp Biol 2008, 211:3077-3084.

55. Hwang PP, Lee TH: New insights into fish ion regulation and mitochondrion-rich cells. Comp Biochem Physiol A Mol Integr Physiol 2007 148:479-497.

56. McClelland GB, Craig PM, Dhekney K, Dipardo S: Temperature-and exercise-induced gene expression and metabolic enzyme changes in skeletal muscle of adult zebrafish (Danio rerio). J Physiol 2006, 577:739-751.

57. Tseng YC, Kao ZJ, Liu ST, Chen RD, Hwang PP: Spatial expression and functional flexibility of monocarboxylate transporter isoforms in the zebrafish brain. Comp Biochem Physiol A Mol Integr Physiol 2013, 165:106-118.

58. Nielsen $A L$, Jorgensen $A L$ : Structural and functional characterization of the zebrafish gene for glial fibrillary acidic protein, GFAP. Gene 2003 310:123-132.

59. Trevarrow B, Marks DL, Kimmel CB: Organization of hindbrain segments in the zebrafish embryo. Neuron 1990, 4:669-679.

60. Pacák K, Palkovits M: Stressor specificity of central neuroendocrine responses: implications for stress-related disorders. Endocr Rev 2001 22:502-548. 
61. Herbing l: Effects of temperature on larval fish swimming performance: the importance of physics to physiology. J Fish Biol 2002, 61:865-876.

62. Jonassen TM, Imsland AK, Stefansson SO: The interaction of temperature and fish size on growth of juvenile halibut. J Fish Biol 1999, 54:556-572.

63. Clarke A, Johnston NM: Scaling of metabolic rate with body mass and temperature in teleost fish. J Animal Ecol 1999, 68:893-905.

64. White CR, Alton LA, Frappell PB: Metabolic cold adaptation in fishes occurs at the level of whole animal, mitochondria and enzyme. Proc Biol Sci B 2012, 279:1740-1747.

65. Barrionuevo WR, Burggren WW: $\mathrm{O} 2$ consumption and heart rate in developing zebrafish (Danio rerio): influence of temperature and ambient $\mathrm{O}_{2}$. Am J Physiol Regul Integr Comp Physiol 1999, 276:R505-R513.

66. Sangiao-Alvarellos S, Laiz-Carrión R, Guzmán JM, del Río MPM, Miguez JM, Mancera JM, Soengas JL: Acclimation of S. aurata to various salinities alters energy metabolism of osmoregulatory and nonosmoregulatory organs. Am J Physiol Regul Integr Comp Physiol 2003, 285:R897-R907.

67. Tseng YC, Lee JR, Chang JCH, Kuo CH, Lee SJ, Hwang PP: Regulation of lactate dehydrogenase in tilapia (Oreochromis mossambicus) gills during acclimation to salinity challenge. Zool Stud 2008, 47:473-480.

68. Polakof S, Mommsen TP, Soengas JL: Glucosensing and glucose homeostasis: from fish to mammals. Comp Biochem Physiol B Biochem Mol Biol 2011, 160:123-149.

69. Polakof S, Panserat S, Soengas JL, Moon TW: Glucose metabolism in fish: a review. J Comp Physiol B 2012, 182:1015-1045.

70. Ivanov A, Mukhtarov M, Bregestovski P, Zilberter Y: Lactate effectively covers energy demands during neuronal network activity in neonatal hippocampal slices. Front Neuroenergetics 2011, 3:2.

71. Gladden LB: Lactate metabolism: a new paradigm for the third millennium. J Physiol 2004, 558:5-30.

72. Newington JT, Harris RA, Cumming RC: Reevaluating metabolism in Alzheimer's disease from the perspective of the astrocyte-neuron lactate shuttle model. J Neurodegenr Dis 2013, 2013:234572.

73. Coco M, Caggia S, Musumeci G, Perciavalle V, Graziano ACE, Pannuzzo G, Cardile V: Sodium L-lactate differently affects brain-derived neurothrophic factor, inducible nitric oxide synthase, and heat shock protein $70 \mathrm{kDa}$ production in human astrocytes and SH-SY5Y cultures. J Neurosci Res 2013, 91:313-320

74. Umezawa T, Kato A, Ogoshi M, Ookata K, Munakata K, Yamamoto Y, Islam Z, Doi $\mathrm{H}$, Romero MF, Hirose $\mathrm{S}: \mathrm{O}_{2}$-filled swimbladder employs monocarboxylate transporters for the generation of $\mathrm{O}_{2}$ by lactate-induced root effect hemoglobin. PLoS One 2012, 7:e34579,

75. Halestrap AP: The monocarboxylate transporter family-structure and functional characterization. IUBMB Life 2012, 64:1-9.

76. Garcia CK, Brown MS, Pathak RK, Goldstein JL: CDNA cloning of MCT2, a second monocarboxylate transporter expressed in different cells than MCT1. J Biol Chem 1995, 270:1843-1849.

77. Jackson V, Price N, Carpenter L, Halestrap A: Cloning of the monocarboxylate transporter isoform MCT2 from rat testis provides evidence that expression in tissues is species-specific and may involve post-transcriptional regulation. Biochem J 1997, 324:447-453.

78. Pellerin L, Pellegri G, Martin J-L, Magistretti PJ: Expression of monocarboxylate transporter mRNAs in mouse brain: support for a distinct role of lactate as an energy substrate for the neonatal vs. adult brain. Proc Natl Acad Sci U S A 1998, 95:3990-3995.

79. Hansen HP: Determination of oxygen. Methods of Seawater Analysis. In Edited by Grasshoff K, Kremling K, Ehrhardt M. Weinheim: Verlag Chemie; 1999:75-89.

80. Tang R, Dodd A, Lai D, McNabb WC, Love DR: Validation of zebrafish (Danio rerio) reference genes for quantitative real-time RT-PCR normalization. Acta Biochim Biophys Sin (Shanghai) 2007, 39:384-390.

doi:10.1186/s12983-014-0053-1

Cite this article as: Tseng et al:: Brain functioning under acute hypothermic stress supported by dynamic monocarboxylate utilization and transport in ectothermic fish. Frontiers in Zoology 2014 11:53.

\section{Submit your next manuscript to BioMed Central and take full advantage of:}

- Convenient online submission

- Thorough peer review

- No space constraints or color figure charges

- Immediate publication on acceptance

- Inclusion in PubMed, CAS, Scopus and Google Scholar

- Research which is freely available for redistribution

Submit your manuscript at www.biomedcentral.com/submit
C Biomed Central 